\title{
A 10-Year Austral Summer Climatology of Observed and Modeled Intraseasonal, Mesoscale, and Diurnal Variations over the Maritime Continent
}

\author{
Claire L. Vincent AND TODD P. LANE \\ School of Earth Sciences, and ARC Centre of Excellence for Climate System Science, The University of Melbourne, \\ Melbourne, Victoria, Australia
}

(Manuscript received 21 September 2016, in final form 22 December 2016)

\begin{abstract}
The Maritime Continent is one of the wettest regions on the planet and has been shown to be important for global budgets of heat and moisture. Convection in the region, however, varies on several interrelated scales, making it difficult to quantify the precipitation climate and understand the key processes. For example, the diurnal cycle in precipitation over the land varies substantially according to the phase of the Madden-Julian oscillation (MJO), and the diurnal precipitation cycle over the water is coupled to that over the land, in some cases for distances of over $1000 \mathrm{~km}$ from the coast.

Here, a 10-yr austral summer climatology of diurnal and MJO-scale variations in rain rate over the land and sea over the Maritime Continent is presented. The climatology is based on mesoscale model simulations with a horizontal grid length of $4 \mathrm{~km}$ and satellite precipitation estimates. The amplitude of the observed diurnal precipitation cycle is shown to reach a maximum just prior to the MJO active phase, with a weaker secondary maximum after the MJO active phase. Although these two maxima also exist in the modeled diurnal precipitation cycle, there is less difference between the maxima before and after the MJO active phase than in the observations. The modeled sea-breeze circulation is also shown to possess approximately equal maxima just before and just after the MJO active period, suggesting that the asymmetry of the diurnal precipitation cycle about the $\mathrm{MJO}$ active period is related more to moisture availability than kinematic forcing.
\end{abstract}

\section{Introduction}

The Maritime Continent (MC) plays an important role as a heat and moisture source that can impact global circulation and modulate planetary-scale variability (Neale and Slingo 2003). However, despite its importance, large errors are commonly found in the MC region in global and regional climate and weather models (e.g., Gianotti et al. 2012; Holloway et al. 2012; Nguyen et al. 2015; Dirmeyer et al. 2012; and others). One likely source of these errors arises from the difficulty in modeling the interscale interactions between intraseasonal variability and diurnally forced mesoscale variability such as the sea-breeze circulation and mountain/valley winds.

The diurnal cycle exerts a dominating influence on the MC. The diurnal precipitation cycle in the tropics is controlled by the response to radiative heating and the periodic organization of convection both onshore and offshore by mesoscale phenomena such as the

Corresponding authore-mail: Claire L. Vincent, claire.vincent@ unimelb.edu.au sea-breeze circulation, land/valley breezes, and diurnal gravity waves. Numerous studies have demonstrated a general pattern of an afternoon or evening peak in precipitation over the land and an early morning peak in precipitation over the sea in the tropics (e.g., Yang and Slingo 2001; Mapes et al. 2003; Love et al. 2011; Qian 2008)

One of the major sources of intraseasonal variability in the MC is the Madden-Julian oscillation (MJO). The MJO is associated with a large-scale envelope of cloudiness and convection that propagates from the Indian Ocean to the Pacific Ocean with a period of around 30-90 days (Zhang 2013). The MJO has been observed to weaken as it reaches the MC (e.g., Oh et al. 2013), and some MJO events that initiate in the Indian Ocean do not propagate through the MC at all (Feng et al. 2015). The MJO has been shown to interact strongly with the diurnal precipitation, and both the moisture availability and the amount of shortwave radiation at the surface are modulated by the large-scale envelope of cloudiness. The main goal of this work is to examine the relationships between diurnal and MJOscale variability of precipitation over the MC. This topic 
was addressed by Peatman et al. (2014), who argued that the diurnal precipitation cycle was responsible for $80 \%$ of the total rainfall variation in the MC, partly explaining the enhanced precipitation over the $\mathrm{MC}$ islands that was observed ahead of the main MJO envelope. Birch et al. (2016) and Vincent and Lane (2016a) also studied this effect in mesoscale model simulations, and both argued that clearer skies and a moist environment ahead of the main MJO envelope promoted favorable conditions for the diurnal precipitation cycle, which was then suppressed by the decrease in solar insolation with the onset of the cloudier MJO active period.

It has also been proposed that upscale interactions between the diurnal cycle and the MJO may play a role in the poor representation of the MJO in GCMs. For example, Oh et al. (2013) showed that in simulations where the diurnal cycle was damped by nudging toward daily averaged TRMM rain rates and NCEP reanalysis prognostic variables, the MJO maintained its strength as it reached the MC rather than weakening. In addition, Majda and Yang (2016) used a simplified model to show that the temperature anomalies associated with the MJO and the upscale effect of the diurnal cycle cancelled one another, possibly explaining the weakening of the MJO as it moved through the MC.

The propagation of the MJO in global or regional climate models or analyses has been addressed in a number of studies. For example, Holloway et al. (2013) examined sensitivity of MJO propagation to parameterization of convection and vertical mixing in the boundary layer in the Met Office Unified Model for horizontal grid lengths between 4 and $40 \mathrm{~km}$. Hovmöller diagrams of precipitation suggested that the MJO propagation was most realistic in the convectionpermitting simulations, even with a horizontal resolution of $12 \mathrm{~km}$, although this result was dependent on the choice of subgrid-scale mixing parameterization. On a much coarser scale, Kim et al. (2014) investigated the amplitude and phase of the MJO in five global reanalysis products relative to GPCP observations and found that all analysis products considered had a smaller MJO amplitude than observed, including in the ERA-Interim reanalysis, which was used to initialize the highresolution simulations in the present study.

Over the MC, validation of MJO propagation in regional climate models is confounded by its multiscale interaction with complex topography and coastlines. Recently, several studies have applied ideas about changes in the diurnal cycle over the land and sea with the passage of the MJO to the problem of model validation. This approach is justified by the suggestion that model skill in simulating the diurnal cycle over the MC may be important for realistic MJO propagation (Majda and Yang 2016). For example, Birch et al. (2016) ran a 10-yr simulation using the Met Office Unified Model with horizontal grid lengths of 12 and $4.5 \mathrm{~km}$ over Sumatra and the Malay Peninsula. They found that decreased solar insolation during the active phases of the MJO led to a suppressed diurnal cycle, consistent with the results of Peatman et al. (2014). Furthermore, they found that the diurnal precipitation peak occurred too late in the day in the 4.5-km model. Peatman et al. (2015) investigated the MJO in the High-Resolution Global Environmental Model (HiGEM) model with horizontal grid length $0.83^{\circ}$ in the latitude direction and $1.25^{\circ}$ in the longitude direction. They applied new diagnostics based on the observational evidence in Peatman et al. (2014) to identify that the diurnal cycle was too weak in the HiGEM model and that the simulated MJO inertia was too great; that is, the model tended to remain in the same MJO phase for too long. Vincent and Lane (2016a) studied the propagation of the MJO through the region surrounding New Guinea during a 30-day period using a mesoscale model with horizontal grid length of $4 \mathrm{~km}$ and found that the maximum diurnal cycle and greatest offshore extent of seaward-propagating precipitation occurred in the few days just prior to and just following the MJO active period. Despite a large wet bias over the land, the main physical processes were modeled realistically.

In this current study, we use a 10-yr simulation of the austral summer (1 December-28 February) over the whole MC region with a horizontal grid length of $4 \mathrm{~km}$. The simulations are unique in covering such a large area at relatively high resolution. The simulations are evaluated relative to the propagation of the MJO and the variation of the diurnal precipitation cycle over the land and sea with the passage of the MJO. The work builds on earlier results of Vincent and Lane (2016a), who investigated a single MJO event over New Guinea; Birch et al. (2016), who ran a 10-yr simulation at similar resolution but over a single MC island; and Peatman et al. (2015), who advocated validating the MJO in models using metrics that incorporated ideas about the evolution of the diurnal precipitation cycle. The simulations are used to develop a climatology of austral summer precipitation and its diurnal and MJO-scale variation. The climatological variation in sea breeze with the MJO over Sumatra and New Guinea is also examined relative to variations in coastal precipitation.

The remainder of this paper is arranged as follows: In section 2, we describe the model setup and the satellite precipitation data used in the analysis. In section 3, maps of the average precipitation and amplitude and phase of the diurnal precipitation cycle are presented for modeled and observed rain rates. In section 4 , modeled and 


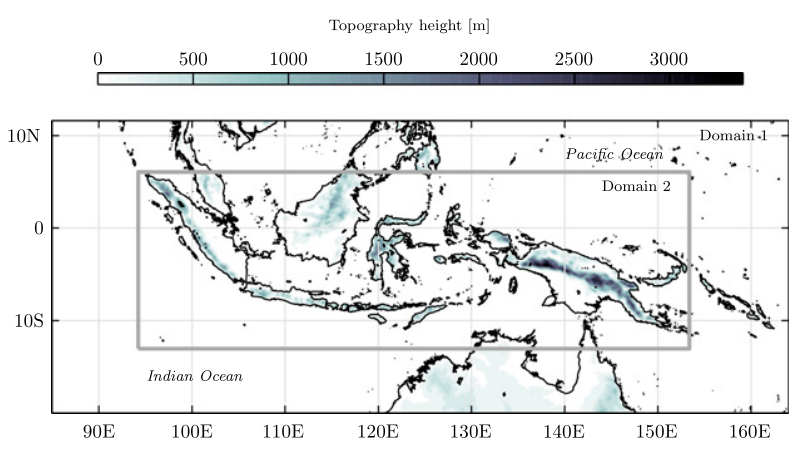

FIG. 1. Model domains. Domain 1 has $12-\mathrm{km}$ horizontal grid spacing, and domain 2 has $4-\mathrm{km}$ horizontal grid spacing.

observed precipitation anomalies are presented as a function of MJO phase. In sections 5 and 6, the areaaveraged diurnal precipitation cycle over the land and sea and averaged offshore precipitation propagation are quantified for selected MC islands, and in section 7, the precipitation is related to variations in the land-seabreeze circulation. Discussion and concluding remarks are given in sections 8 and 9 .

\section{Data and methods}

\section{a. Model setup and sensitivity}

The WRF Model, version 3.5, was used to produce the simulated dataset of austral summer precipitation over the MC. The dataset is freely available online (Vincent and Lane 2016b). Two one-way nested domains with horizontal grid lengths of 12 and $4 \mathrm{~km}$, respectively, were used (see Fig. 1). These two domains have dimensions of $8784 \times 3540 \mathrm{~km}^{2}(732 \times 295$ grid points $)$ and $6564 \times$ $2136 \mathrm{~km}^{2}(1641 \times 534$ grid points $)$, respectively. The results presented here are all from the 4-km domain. The simulations were run with the MYJ planetary boundary layer scheme (Mellor and Yamada 1982), the Betts-Miller cumulus scheme (Janjić 1994) on the outer domain only, the WSM6 microphysics scheme (Hong and Jeong-Ock 2006), the RRTM longwave (Mlawer et al. 1997) and the Goddard shortwave radiation (Chou and Suarez 1994) schemes, and the Noah land surface scheme (Mitchell et al. 2005) (see Table A1, where the model configuration varies from the control run only in the cumulus scheme on the outer domain). The simulations had 79 vertical levels with the lowest levels at 26 , 78 , and $129 \mathrm{~m}$ and the highest model level at $25 \mathrm{~km}$. Boundary conditions and initial conditions for the 12-km domain were provided by the ERA-Interim reanalysis (Dee et al. 2011), and to maintain consistency with observed intraseasonal variability, spectral nudging toward ERA-Interim was performed for the $12-\mathrm{km}$ domain only for wavelengths longer than $1000 \mathrm{~km}$ above the boundary layer, with an inverse nudging time scale of $0.0003 \mathrm{~s}^{-1}$ for all nudged variables. Liu et al. (2012) showed that spectral nudging achieved a better balance between maintaining consistency with large-scale forcing while allowing smaller-scale variance to develop than grid nudging, and Vincent and Hahmann (2015) showed that while grid nudging caused a smoothing of the near-surface wind, spectral nudging mainly influenced longer wavenumbers. Subramanian and Zhang (2014) demonstrated that in a global model, nudging toward ERA-Interim improved the veracity of the MJO propagation. In this study, where we are interested in mesoscale variability, spectral nudging is therefore an ideal tool for constraining MJO-scale variance while allowing mesoscale variance to develop freely. Sea surface temperatures were updated daily using the realtime global sea surface temperature (high resolution) dataset with a horizontal resolution of $0.083^{\circ} \times 0.083^{\circ}$ (Gemmill et al. 2007).

Since the focus of this study is the diurnal precipitation cycle and its mesoscale and intraseasonal variability, model parameters were chosen based mainly on sensitivity tests to the area-averaged diurnal precipitation cycles over the sea and land (see the appendix). Changing the model parameterizations made little difference to biases in the diurnal precipitation cycle on the 4-km domain. The largest differences were seen between the planetary boundary layer schemes, and the MYJ scheme was chosen as a compromise between the diurnal cycle over the land and that over the sea. The choice of model grid spacing of $4 \mathrm{~km}$ was made based on available computational resources and desired domain size and simulation length. Preliminary experiments with 3-km grid spacing showed little improvement in the diurnal precipitation cycle. Moreover, comparisons between 4 - and 1.33-km grid spacing over New Guinea and Darwin by Hassim et al. (2016) suggested little difference between the two resolutions.

The simulations were initialized on 29 November for each season, allowing 2 days of spinup that was discarded. The model was then run continuously until 28 February. Inspection of Hovmöller diagrams showed only slight deterioration of large-scale intraseasonal variability events during the 3-month periods, suggesting that the nudging was sufficient to relax large-scale features toward those in ERA-Interim. Initializing the simulations halfway through the season made little difference to the intraseasonal variability (see the appendix).

\section{b. Satellite precipitation data}

Satellite precipitation estimates are particularly useful over the Maritime Continent due to the sparsity of 
readily available rain gauge observations over the complex topography and the absence of in situ measurements over the sea. Satellite precipitation estimates from the Tropical Rainfall Measurement Mission (TRMM) 3B42 V7 (Huffman et al. 2007; Goddard Space Flight Center 1998) and the Climate Prediction Center morphing technique (CMORPH; Joyce et al. 2004; Climate Prediction Center 2011) were used in the study.

TRMM estimates are derived from passive microwave sensor observations from polar-orbiting satellites, together with brightness temperature measurements from geostationary satellites. An adjustment based on rain gauge measurements is retrospectively applied to the estimates. The data have a temporal resolution of $3 \mathrm{~h}$ and a spatial resolution of $0.25^{\circ} \times 0.25^{\circ}$. TRMM data have been widely used in characterizing the MJO over the MC (e.g., Peatman et al. 2014) and for comparison with and validation of mesoscale and regional climate model simulations and other precipitation datasets (e.g., Vincent and Lane 2016a; Bhatt et al. 2016; Skok et al. 2016; Koo and Hong 2010; Hassim et al. 2016).

CMORPH precipitation estimates are derived from passive microwave signals alone, with high-resolution temporal information provided using propagation estimates from IR scans from geostationary satellites (Joyce et al. 2004). The data have temporal resolution of $30 \mathrm{~min}$ and spatial resolution of $0.08^{\circ} \times 0.08^{\circ}$. Like TRMM, CMORPH has been used in a range of model validation and precipitation studies. Skok et al. (2016) found a dry bias of $10 \%-30 \%$ over continental Europe relative to TRMM, and in particular less precipitation over the European Alps than TRMM. Vincent and Lane (2016a) compared TRMM and CMORPH estimates to rain gauges in New Guinea during a 1-month period and found a systematic overprediction in most locations for CMORPH, with many sites exceeding $10 \mathrm{~mm} \mathrm{day}^{-1}$ and smaller positive and negative biases of less than about $5 \mathrm{~mm}^{-1 a y}{ }^{-1}$ for TRMM. That these results are inconsistent with those of Skok et al. (2016) is unsurprising, given the different meteorological regimes and short test period in Vincent and Lane (2016a).

The diurnal precipitation maximum in satellite precipitation estimates have been shown in various studies to lag rain gauge estimates by $1-4 \mathrm{~h}$, which has been attributed to the use of infrared data that are based on cloud-top temperatures. Pfeifroth et al. (2016) examined the diurnal cycle in several satellite precipitation estimates relative to a high density gauge network in tropical West Africa and found a delay in the timing of peak evening precipitation in most of the products they considered during the monsoon months. For TRMM, they found a lag of $1-2 \mathrm{~h}$ and a smaller lag of around $1 \mathrm{~h}$ for CMORPH. Rauniyar and Walsh (2013), Kikuchi and
Wang (2008), and Gianotti et al. (2012) all discuss the diurnal phase lag in TRMM. No attempt has been made here to correct this lag, which is dependent on the type of precipitation, but results should be interpreted relative to this possible error.

\section{Average precipitation and diurnal precipitation cycle}

The average hourly rainfall over the 10 austral summer seasons from the WRF simulations and the TRMM and CMORPH satellite estimates are shown in Figs. 2a-c. The CMORPH and WRF data, which have native resolutions of 8 and $4 \mathrm{~km}$, respectively, have been averaged to the TRMM $0.25^{\circ} \times 0.25^{\circ}$ grid for the purpose of this and all further comparisons in this paper. The spatial distributions of precipitation from the two satellite estimates are qualitatively similar, despite an average dry bias of $26 \%$ over the land and $13 \%$ over the water in CMORPH relative to TRMM. This dry bias over the land is consistent with the findings of Skok et al. (2016) for continental Europe.

Figures $2 \mathrm{~d}$ and $2 \mathrm{e}$ show the mean difference between WRF and TRMM and WRF and CMORPH. There are notable differences between the WRF simulations and the satellite estimates, both in the spatial distribution and magnitude of the average hourly rainfall. Relative to the satellite precipitation estimates, the WRF Model has a positive precipitation bias over most land areas (34\% for TRMM and $82 \%$ for CMORPH) and a negative precipitation bias over most sea areas (24\% for TRMM and $13 \%$ for CMORPH). The effect over the land is most pronounced near the topographic peaks. Further, the satellite precipitation estimates show a decrease in hourly rainfall over the highest peaks of New Guinea (seen as a paler stripe through the middle of the island), an effect that is much less pronounced in the WRF Model simulations. This region is problematic, since there is also a possibility of errors in the satellite estimates over the steepest and highest topography, and there are few rain gauges in the area for independent validation [see discussion in Vincent and Lane (2016a) and Hassim et al. (2016)]. The satellite estimates also show areas of enhanced rainfall over the east coast of the Malay Peninsula and the west coast of Borneo that are entirely absent in the WRF Model simulations. This region is influenced by both MJO-scale variability and by the Borneo vortex and northeast cold surge (Chang et al. 2005), which may occur too close to the domain boundary to be resolved properly.

A diurnal harmonic was fitted to the average diurnal cycle at each grid point of the three datasets after the WRF and CMORPH data were averaged to the 

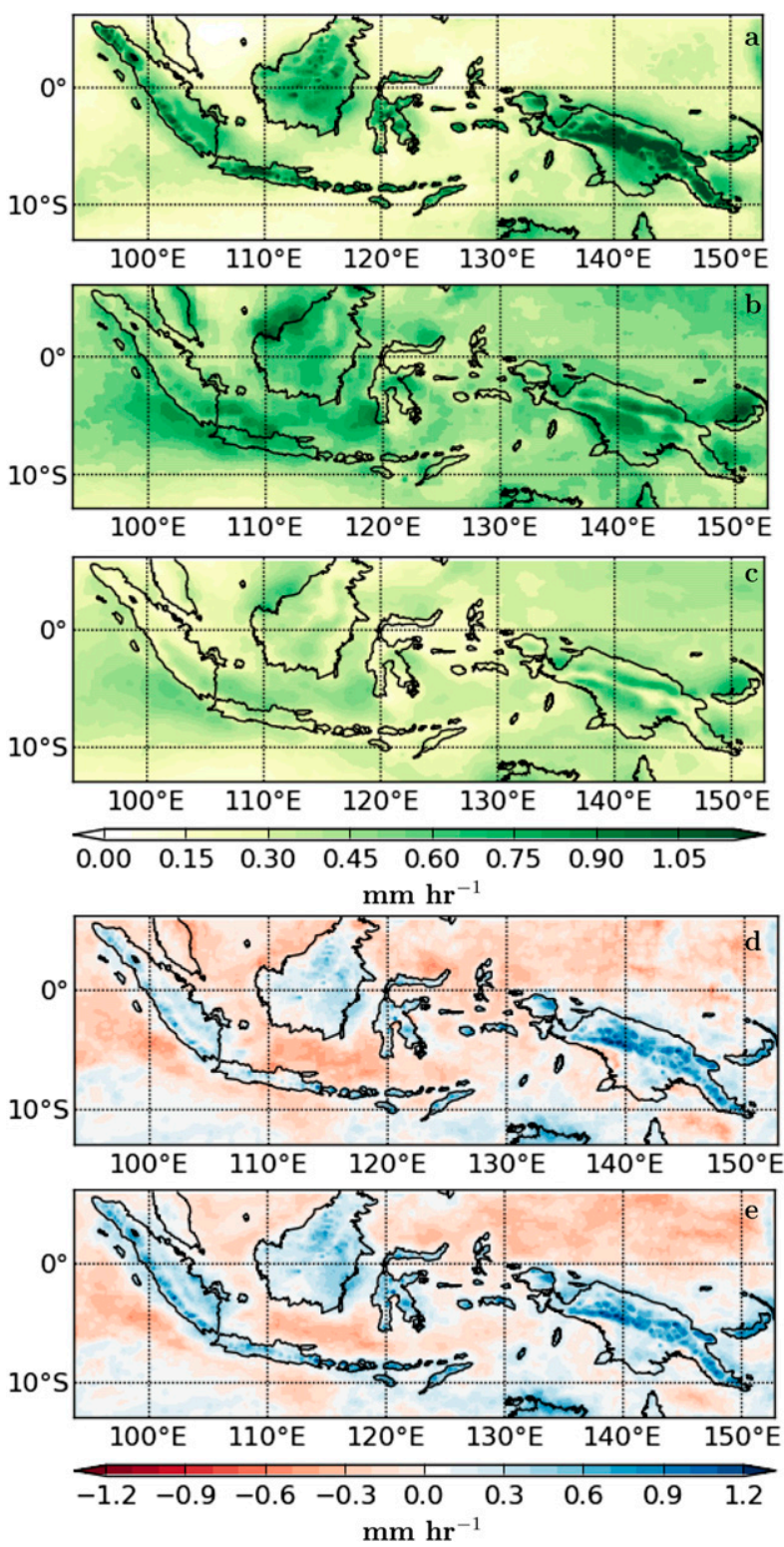

FIG. 2. Average hourly austral summer rainfall $\left(\mathrm{mm} \mathrm{h}^{-1}\right)$ for (a) WRF, (b) TRMM, (c) CMORPH, (d) WRF-TRMM, and (e) WRF-CMORPH. WRF and CMORPH data are averaged onto the TRMM grid.

TRMM grid. The three datasets have different temporal resolutions, and when converted to local solar time (LST), the timing of the observations varies with longitude. To address these discrepancies, the time axis of each grid point was first converted to LST, and the diurnal precipitation cycle was interpolated to hourly values between 0000 and 2300 LST. The peak amplitude of the daily precipitation cycle and timing of the maximum of the diurnal harmonic are shown in Figs. 3 and 4 , respectively. The maximum peak amplitudes of the diurnal precipitation cycle (Fig. 3) are found over land and gradually decrease over the water with distance from the coast. Relative to those in the satellite precipitation estimates, the amplitudes in the WRF Model are too large, particularly over the highest topographic peaks. However, over the sea the errors are smaller, and the gradual decrease in amplitude with distance from the coast is similar in the simulated and observed data.

The spatial distribution of the timing of the average daily maximum precipitation is remarkably similar in all three datasets (Fig. 4). Over land, the maximum precipitation is found in the afternoon and evening, while bands of successively later precipitation peaks are found around all coastlines, ranging from around 0500 LST near the coast to around 1400 LST several hundred kilometers from the coast. Regions where the amplitude of the diurnal precipitation cycle is less than $0.1 \mathrm{~mm} \mathrm{day}^{-1}$ have been colored white. These results are consistent with earlier studies, including Yang and Slingo (2001) and Love et al. (2011), who showed offshore-propagating precipitation in the tropics, and Gille et al. (2005), who showed similar patterns in the offshore propagation of the maximum sea-breeze anomaly. The differences in the time of the daily precipitation maximum (Fig. 5) suggest that the modeled precipitation peak is systematically early over most land areas, which we show in section 5 is related more to rapid intensification of precipitation after it initiates than to errors in the timing of initiation itself. The largest errors of up to $6 \mathrm{~h}$ coincide with the slopes of the highest peaks of topography in New Guinea, Sulawesi, Borneo, and Sumatra, while smaller errors of $1-2 \mathrm{~h}$ are found over Java and some of the smaller MC islands. Note that there may also be timing errors of up to $4 \mathrm{~h}$ in the observation data, in particular over the steep topography, although this is not sufficient to explain all the differences in timing. The large errors around Sulawesi are noteworthy and may be due to its very complex topography and coastline and location between the larger islands of Borneo and New Guinea. There is extremely good agreement between TRMM and CMORPH (note the finer contour scale in Fig. 5c), with the largest differences only around $1 \mathrm{~h}$ and in many cases along the coast, although both products may be subject to some of the same biases.

Interestingly, the model errors are smaller in the nearcoastal areas immediately adjacent to these large errors associated with steep topography, consistent with results in Vincent and Lane (2016a) and Hassim et al. (2016), who showed that offshore-propagating precipitation near the coast is associated with convergence from drainage flows and destabilization aloft from the cooling phase of the land-sea-breeze circulation. The errors in 

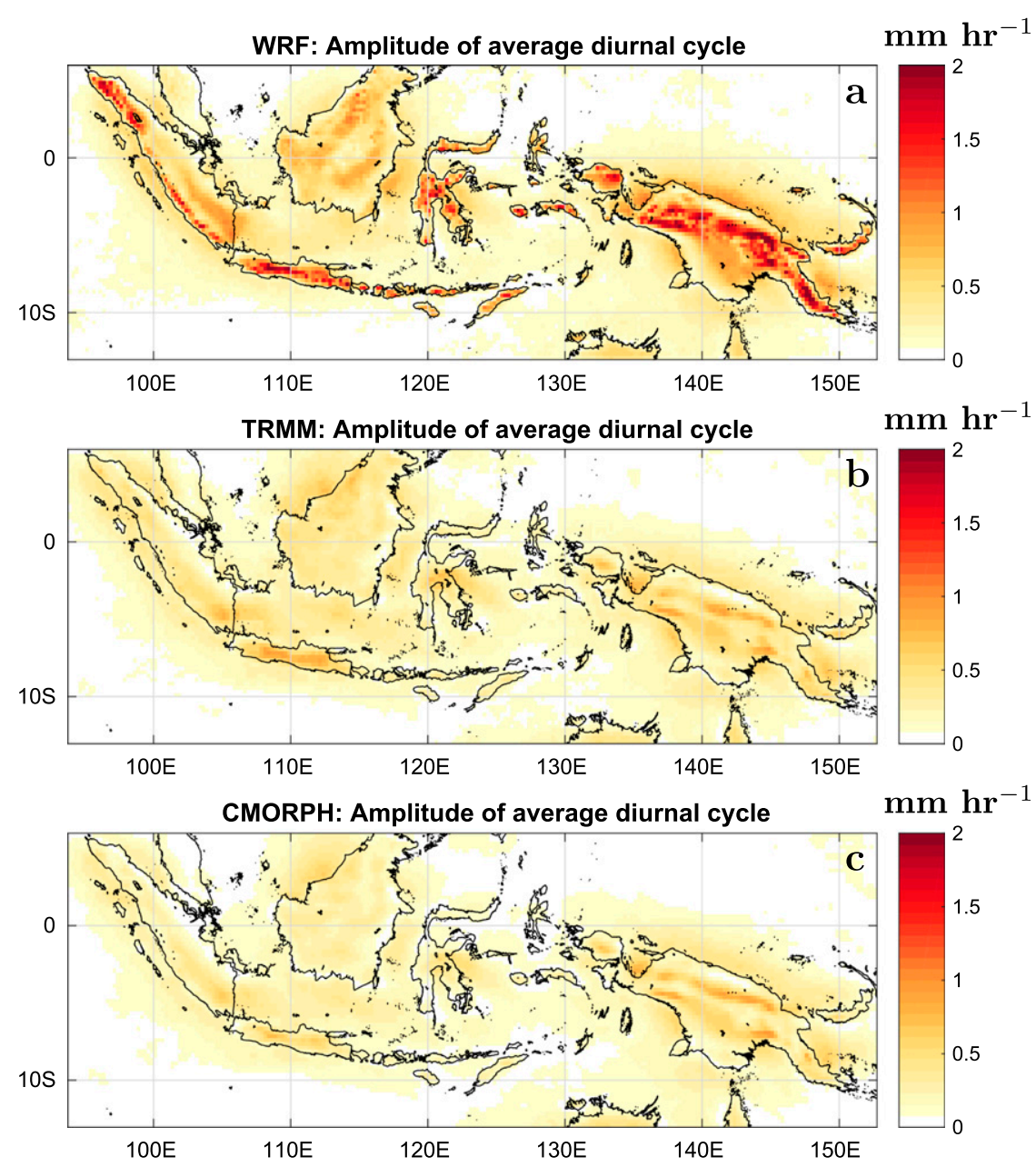

FIG. 3. Average amplitude of the austral summer diurnal precipitation cycle $\left(\mathrm{mm} \mathrm{h}^{-1}\right)$ for (a) WRF,

(b) TRMM, and (c) CMORPH. WRF and CMORPH data are averaged onto the TRMM grid.

the timing of these offshore flows will not necessarily be affected by the rate of intensification and early peak in precipitation over the land, being related to dry dynamics and not necessarily convective-scale processes.

\section{Precipitation anomalies as a function of MJO phase}

In this section, the variation in daily rainfall anomaly with MJO phase is examined (Fig. 6). The MJO is classified according to the eight phases defined by Wheeler and Hendon (2004, hereafter WH04), grouped into the pairs $8-1,2-3,4-5$, and $6-7$ for brevity. Only days where the amplitude of the MJO $>1$, as defined by WH04, are included. The $\mathrm{MJO}$ active phases over the $\mathrm{MC}$ range from 3 to 5 over Sumatra to 5 to 6 over New Guinea, following Rauniyar and Walsh (2013).

Both the WRF Model (Figs. 6a,d,g,j) and the satellite estimates (Figs. 6b,e,h,k and 6c,f,i,l) show that the precipitation anomalies over the land lead those over the water, as already noted by Peatman et al. (2014). For example, in phases 8-1 (Figs. 6a-c) there are positive precipitation anomalies over the major MC islands, while there are still negative anomalies over most water areas. In phases 2-3 (Figs. 6d-f), the onset of the main $\mathrm{MJO}$ envelope is seen over the far western part of the MC, while the positive anomalies over Sulawesi and New Guinea have strengthened. Although these trends are consistent between the model and observations, the WRF Model shows positive precipitation anomalies over the sea to the northeast of New Guinea, in contrast to the negative anomalies seen in the satellite estimates.

In phases 4-5 (Figs. 6g-i), the main envelope of the MJO has moved over the MC, but negative anomalies are already seen over Sumatra and Borneo. This trend is reproduced in the simulations, but the positive precipitation anomalies over the sea are weaker than 


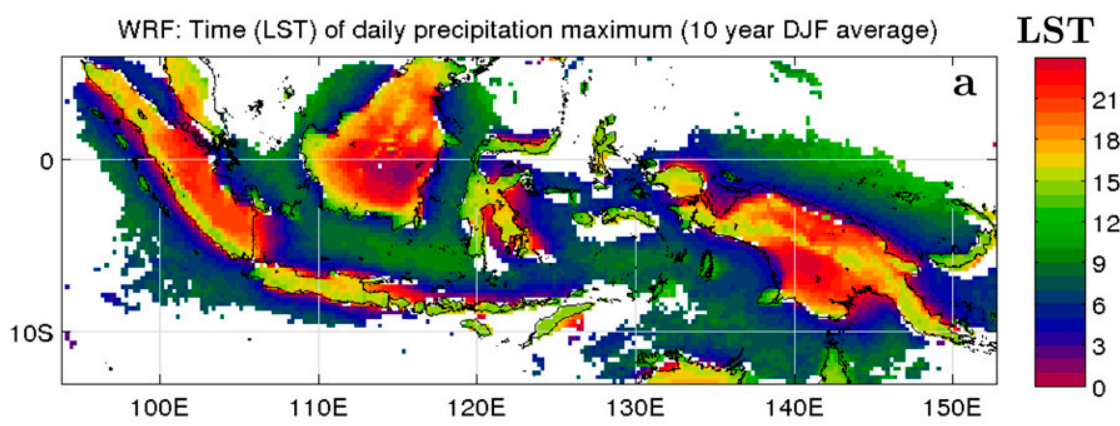

TRMM: Time (LST) of daily precipitation maximum (10 year DJF average)

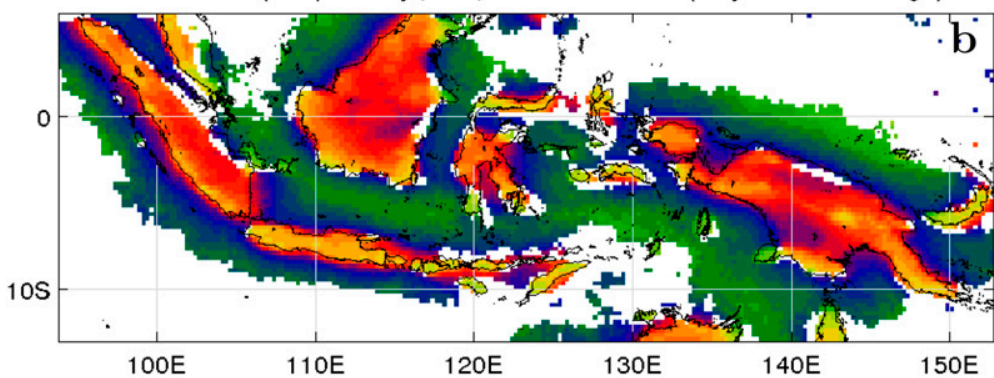

LST

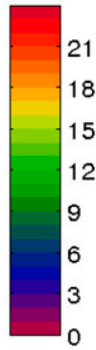

CMORPH: Time (LST) of daily precipitation maximum (10 year DJF average)

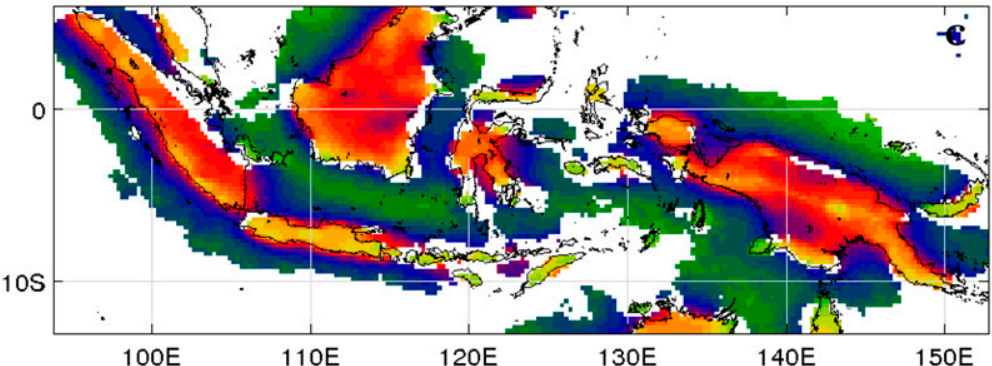

LST

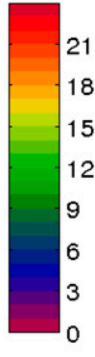

FIG. 4. Timing of the maximum of the fitted diurnal harmonic to the austral summer diurnal precipitation cycle (a) WRF, (b) TRMM, and (c) CMORPH. Contours show time of the daily precipitation maximum in local solar time. WRF and CMORPH data are averaged onto the TRMM grid. Areas where the diurnal amplitude is less than $0.1 \mathrm{~mm} \mathrm{day}^{-1}$ are shaded white.

in the satellite estimates. In particular, over the northeastern portion of the domain, the oceanic rainfall anomaly is poorly simulated in these phases, with portions having anomalies of the wrong sign. This is the largest discrepancy over all phases and locations and explains a large part of the average errors in these locations as well (cf. Fig. 2). Wu and Hsu (2009) showed that this region exhibits a maximum in 20-100-day, filtered, zonal, 850-hPa wind variance, which they attribute to the track of the MJO moving southward east of Sumatra and then northward to the east of New Guinea. This southward deflection of the path of MJO variance may not be fully included within our simulation domain, possibly explaining this large error northeast of New Guinea. By phases 6-7 (Figs. 6j-1), negative anomalies are seen throughout most of the MC in both the model and satellite estimates.
Overall, with the exception of the northeast portion of the domain in phases $4-5$, the model reproduces the rainfall anomalies with the passage of the MJO very well. This agreement is despite some notable errors in the mean precipitation (e.g., Fig. 2) and lends support for using these simulations to understand the key processes.

\section{Diurnal precipitation cycle over the largest Maritime Continent islands}

The analyses in the previous sections have demonstrated that the MJO and the diurnal cycle are both major drivers of rain-rate variability in the MC. Here, we examine the bivariate response of the rain rate to time of day and MJO phase. The area-averaged rain rate as a function of time of day and MJO phase is calculated 

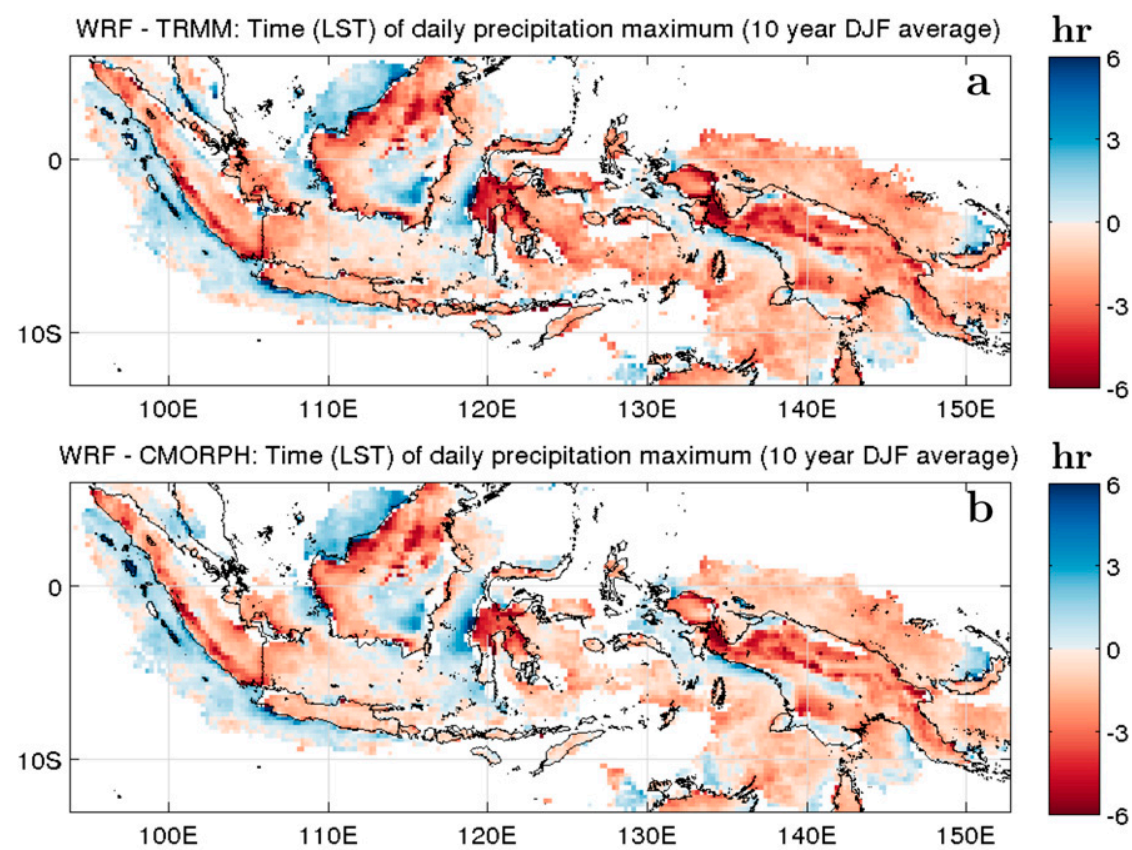

TRMM - CMORPH: Time (LST) of daily precipitation maximum (10 year DJF average) $\mathrm{hr}$

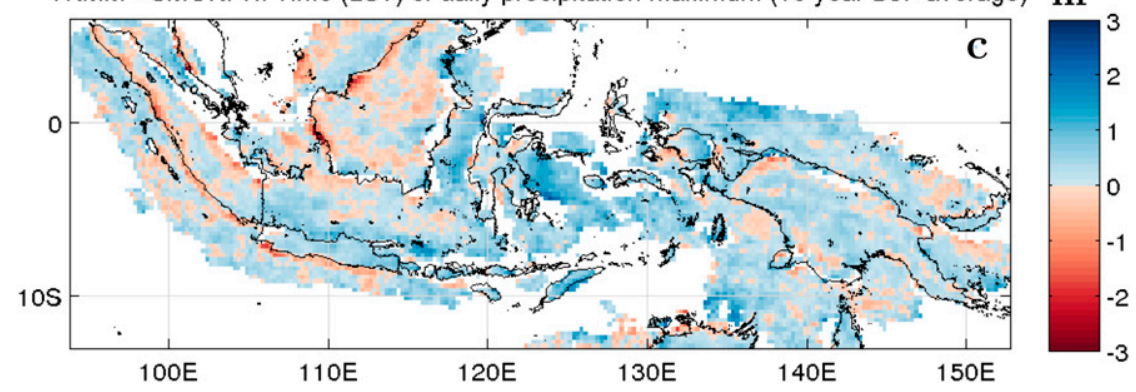

FIG. 5. Difference in timing of the austral summer diurnal precipitation maximum: (a) WRFTRMM, (b) WRF-CMORPH, and (c) TRMM-CMORPH. Red colors indicate a lead in the model timing relative to observations, and blue colors indicate the reverse. WRF and CMORPH data are averaged onto the TRMM grid.

for each of the boxes in Fig. 7 for land and water points around Java, Sumatra, and New Guinea (Figs. 8, 9, 10). There are common themes between the relative rain rates and rain areas over the three islands. The timing of the diurnal maximum over the land occurs earlier in the WRF simulations than in the satellite estimates. This effect is most pronounced over New Guinea where the difference in timing of the diurnal maximum is up to $6 \mathrm{~h}$ and least pronounced over Java where it is $1-2 \mathrm{~h}$, consistent with Fig. 5. This is a recognized problem in the WRF Model that has been discussed by Vincent and Lane (2016a) and others.

Further, the satellite estimates and the WRF Model show the maximum afternoon or evening rainfall over the land occurring around one MJO phase ahead of the main convective envelope over the sea. This is consistent with the results of Peatman et al. (2014) and Birch et al.
(2016) and others, who have shown an enhanced diurnal precipitation cycle prior to the onset of the main MJO envelope. There is some evidence of a double peak in precipitation over the land before and after the MJO active period, particularly over Sumatra and Java. This double peak was not found by Peatman et al. (2014), although their analysis is averaged over a larger area, and some of the variation in mean rain rate and diurnal amplitude with MJO phase may have been obscured by differences between the islands. The maximum WRF precipitation over the land appears to occur half to one MJO phase later than the observed, suggesting a slightly erroneous response in the WRF Model to the evolution in dynamic, thermodynamic, and radiative processes as the MJO approaches. Figures 8 to 10 also suggest that although there is some variation in the timing of the onset of heavy rainfall over the land during the 
WRF
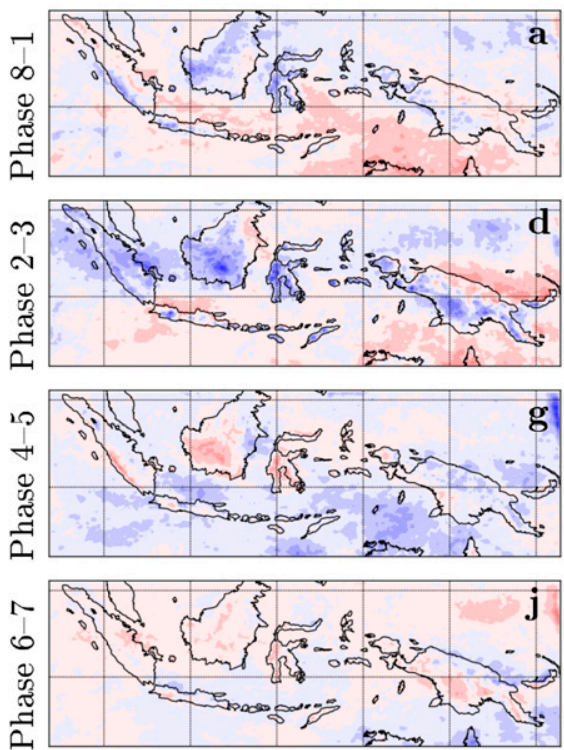

TRMM
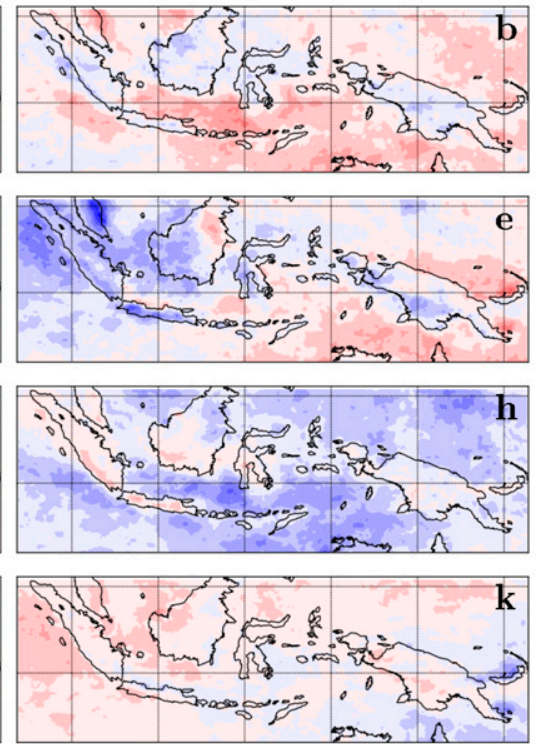

CMORPH
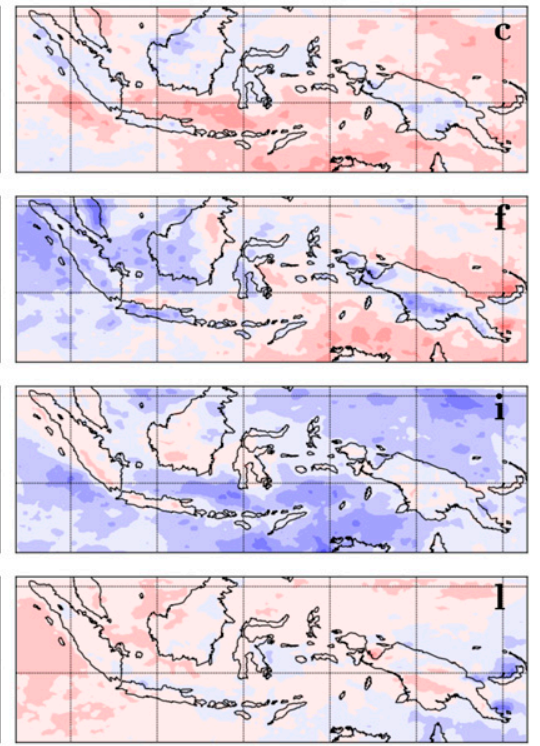

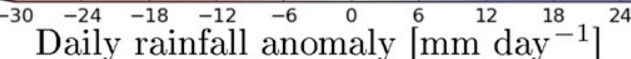

FIG. 6. Austral summer precipitation anomalies by MJO phase for (a),(d),(g),(j) WRF, (b),(e),(h),(k) TRMM, and (c),(f),(i),(l) CMORPH. Anomalies are taken from the December-February average for each season.

afternoon, the timing of the peak precipitation is remarkably invariant with MJO phase.

Despite commonalities across the three islands, there are also some interesting differences between them. Over Sumatra, the precipitation over the sea in the WRF Model (Fig. 9d) reaches a maximum at around 0600 LST in MJO phase 3 and nearly ceases between 1500 and 2000 LST. In the satellite estimates (Figs. 9e,f), a much larger diurnal peak in precipitation over the sea is seen between 0000 and 0700 LST, and precipitation greater than $0.3 \mathrm{~mm} \mathrm{~h}^{-1}$ continues throughout the day in MJO phases 2, 3, and 4. This may be because the southwest side of Sumatra is more influenced by oceanic processes during the westerly burst of the MJO due to the onshore wind component. Over Java, the peak precipitation over the sea occurs in MJO phase 4 (CMORPH and TRMM) or 5 (the WRF Model), while over Sumatra the peak precipitation over the sea occurs in phase 3 (CMORPH, TRMM, and the WRF Model), despite the close proximity of the two islands. This difference is consistent with $\mathrm{Wu}$ and Hsu (2009), who show MJO precipitation, OLR, and wind anomalies affecting the sea to the southwest of Sumatra one or two phases before the anomalies appear to the south of Java and the northeast of New Guinea.

To further explore the differences in diurnal rainfall variability between the WRF Model and the satellite estimates, the area-averaged rain rate and area fraction of rain rate $>0.5 \mathrm{~mm} \mathrm{~h}^{-1}$ are calculated for Sumatra and Borneo for WRF and CMORPH (Fig. 11). These two

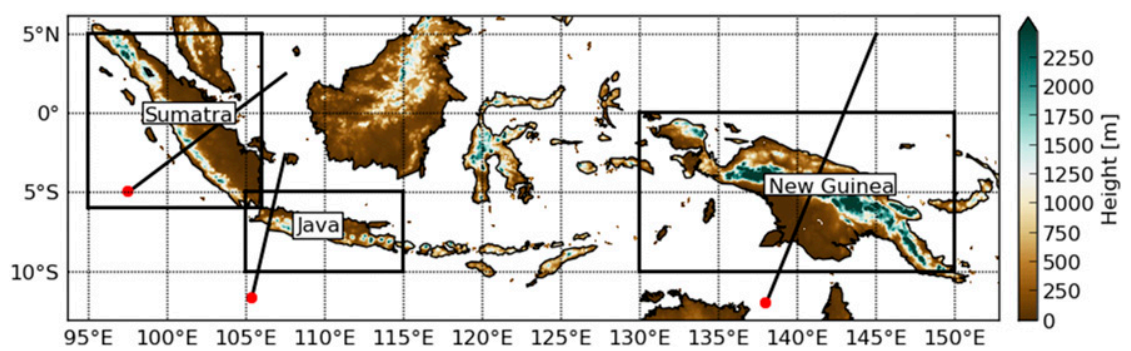

FIG. 7. Boxes for area averages of diurnal precipitation cycle and rain area and transects through Java, Sumatra, and New Guinea. 
Average rain-rate over land
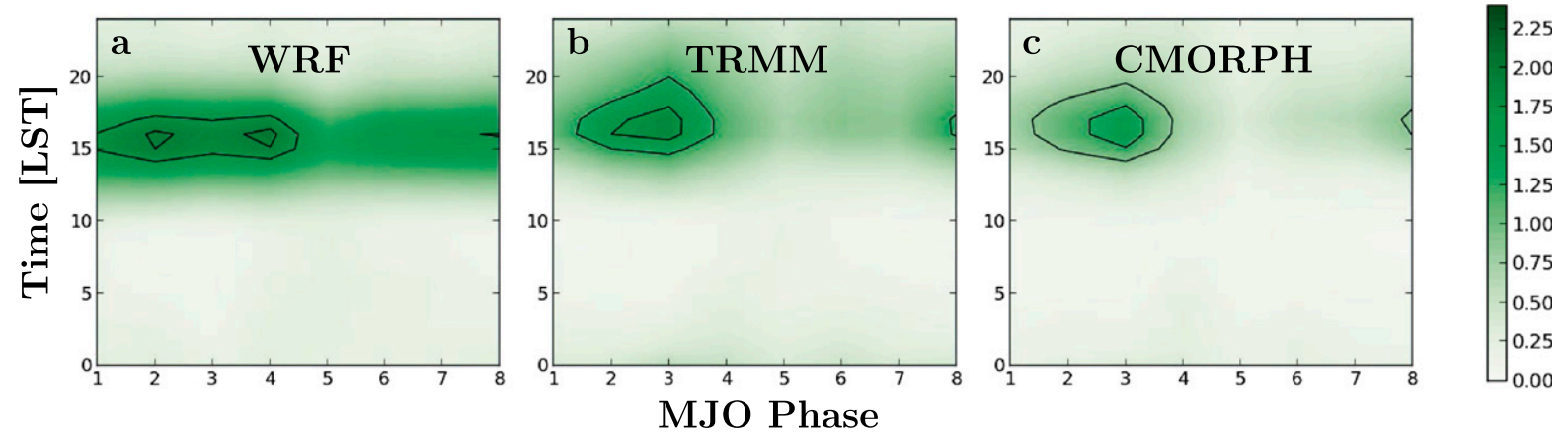

Average rain-rate over sea
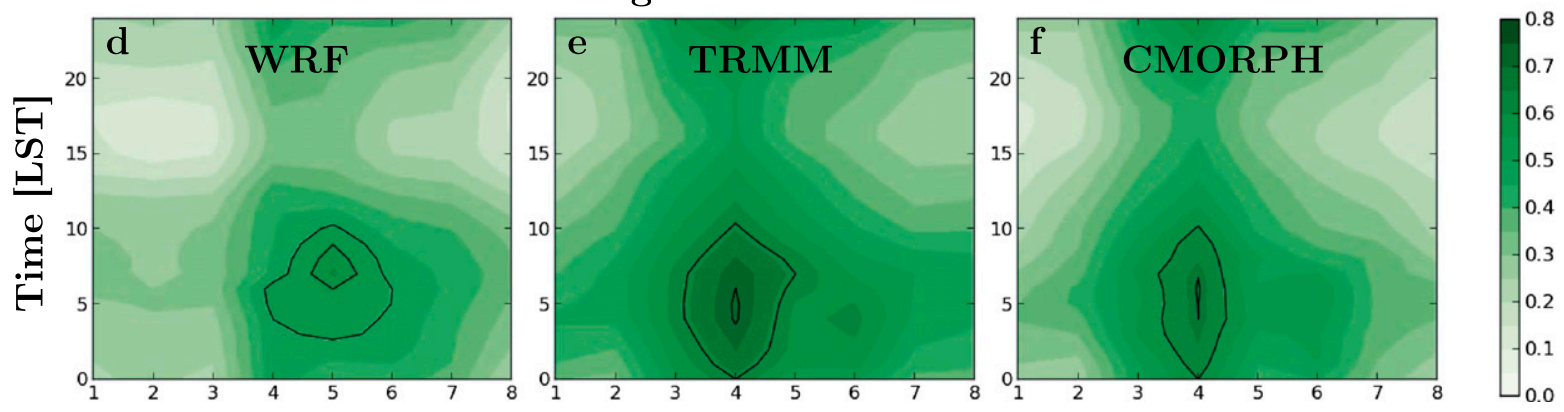

MJO Phase

FIG. 8. Average austral summer variation in rain rate with time of day and MJO phase for (a)-(c) land points and (d)-(f) water points in the box surrounding Java in Fig. 7, for MJO amplitude $>1$. Black contours show the 95th and 99th percentiles of hourly rain rate.

islands represent the elongated landform with steep topography running parallel to the coast, typical of several of the MC islands and a larger landmass, respectively. However, the islands are oriented differently with respect to the westerly wind burst of the MJO, which may cause them to respond differently to the MJO. Over both islands, the observed rain rate increases slowly between 0900 and 1300 LST and then increases more rapidly until around 1700 LST. Over Sumatra (Fig. 11a), the rain rate then decreases, while over Borneo (Fig. 11b) there is a local maximum in rain rate at 1700 LST followed by global maximum at 2100 LST. From 2100 LST, the rain rate decreases over both islands until 0900 LST. The two distinct slopes in observed rain rate from 0900 to 1300 LST and from 1300 to 1700 LST might be indicative of the effect of convergence from mountain winds earlier in the day and convergence from the sea breeze later in the day. The observed rain-area fraction follows a different evolution: it increases more rapidly than the rain rate after $0900 \mathrm{LST}$, then levels out between 1200 and 1300 LST before increasing rapidly again, and then increases gradually to a peak around 1800 LST and a second peak around 2300 LST. Interestingly, when the rain rate starts to decrease after
2100 LST, the rain area is still increasing, suggestive of a transition to widespread, stratiform precipitation.

The simulated rain rate and rain area also begin to increase at around 0900 LST over both islands but much more rapidly, leading to a peak in both rain rate and rain area at 1500-1600 LST. Over Sumatra, there is a steady decrease in rain rate and rain area after the maximum, with no indication of a transition to stratiform precipitation. Over Borneo, the rain-rate and rain-area curves flatten out after the peak, which may indicate a better simulated transition to stratiform precipitation facilitated by the larger land area of Borneo relative to Sumatra. It is interesting to note that over Borneo, both observed and simulated rain rates have some sign of a global and secondary maximum at around 1700 and 2100-2200 LST, respectively, but that the relative magnitude of the simulated maxima are reversed compared to the observed peaks. Thus, despite the reasonable physical consistency in the shape of the two curves, the error in the timing of the global precipitation maximum is $4-5 \mathrm{~h}$, illustrating that the partitioning between convective and stratiform precipitation is critical to correctly simulating the phase of the diurnal precipitation cycle. 
Average rain-rate over land
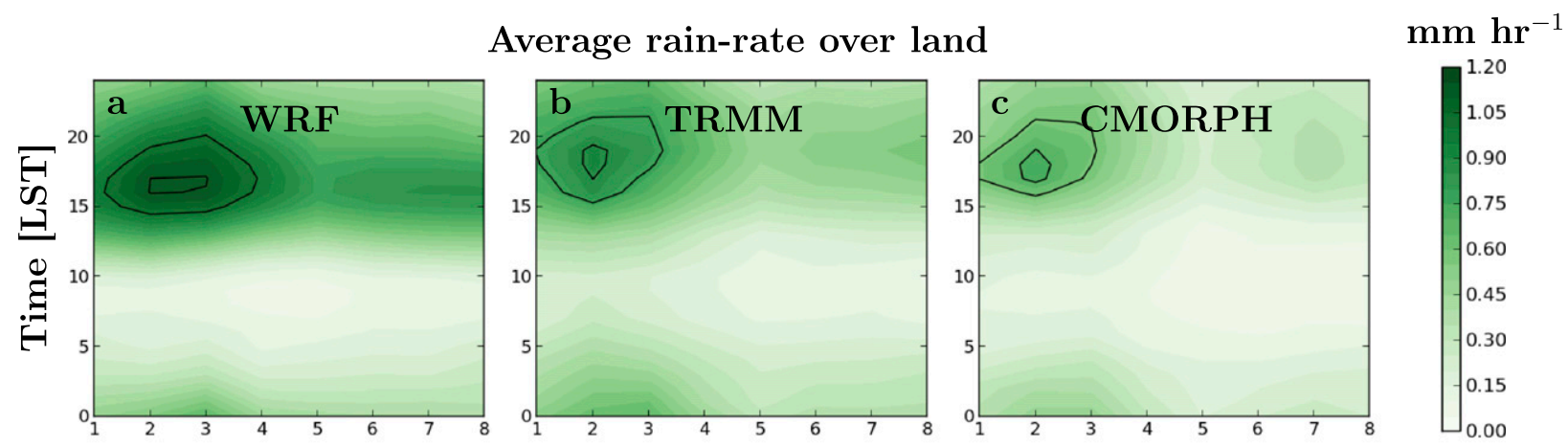

MJO Phase

Average rain-rate over sea
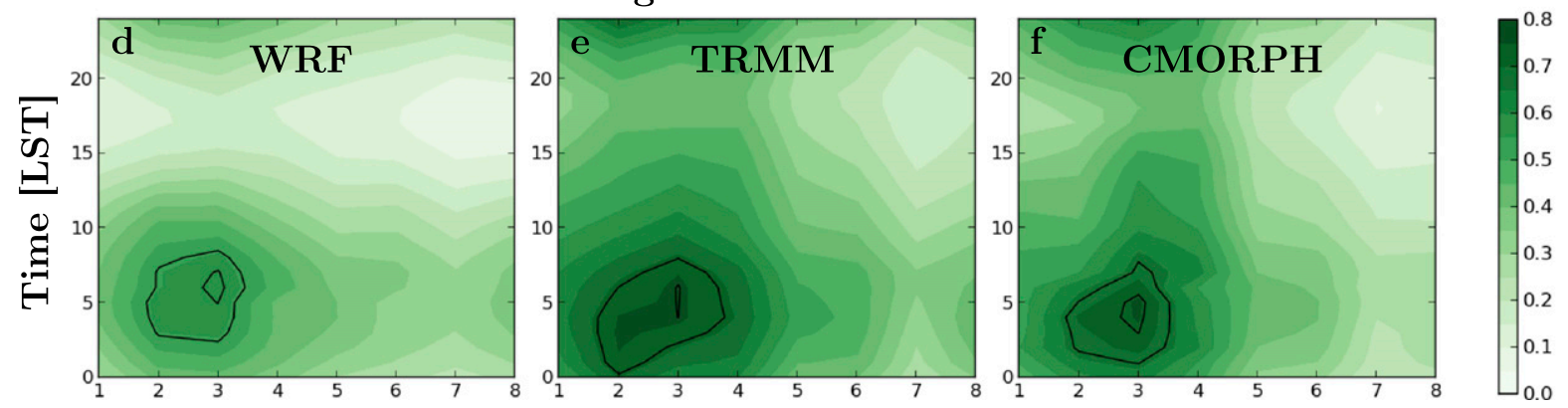

MJO Phase

FIG. 9. As in Fig. 8, but for Sumatra.

\section{Offshore-propagating precipitation from Maritime Continent islands}

Offshore propagation of precipitation during the night and early morning has been addressed in a number of studies [including Yang and Slingo (2001), Love et al. (2011), Mapes et al. (2003), Vincent and Lane (2016a), and Hassim et al. (2016)] and has been shown to be a persistent feature of the diurnal variation in coastal precipitation in the tropics. In the MC, the close proximity of the islands to one another means that a large fraction of the sea will be influenced by these coastal processes, as shown in Fig. 4 and by Bergemann and Jakob (2016). Several mechanisms have been proposed to explain the offshore propagation. Within about the first $100 \mathrm{~km}$ of the coast, the propagation appears to be caused by convergence associated with the density current from the land and valley breezes (e.g., Qian 2008; Zhou and Wang 2006; Ichikawa and Yasunari 2008). Farther offshore, diurnally varying precipitation appears to be associated with destabilization due to the upward and outwards propagation of the cooling phase of the land-sea-breeze circulations as diurnal gravity waves (e.g., Mapes et al. 2003; Yang and Slingo 2001). Vincent and Lane (2016a) detected two distinct propagation speeds associated with the slower nearshore density current (3-5 m s$\left.{ }^{-1}\right)$ and the faster far offshore gravity wave $\left(12-18 \mathrm{~m} \mathrm{~s}^{-1}\right)$ to the northeast of New Guinea. They hypothesized that while the gravity wave signature was always present in wind and potential temperature anomalies, the resultant precipitation was heavier during the lead-up and active MJO phases due to the higher moisture availability. Here, we place the case study results of Vincent and Lane (2016a) in a climatological context for several MC islands.

In Figs. 12 to 14, the average rain rate on the transects through Java, Sumatra, and New Guinea (indicated in Fig. 7) is plotted as a function of time of day and alongtransect distance for WH04 phases 8-1, 2-3, 4-5, and 6-7 (with WH04 amplitude greater than 1). Transects run from southwest to northeast. Topography height is shown on the secondary $y$ axis. The analysis is replicated for the WRF Model, TRMM, and CMORPH, where all data are averaged to the TRMM grid prior to calculating the cross sections.

Over both Java and Sumatra (Figs. 12,13), the heaviest precipitation is found over the land in WH04 phases 2-3. This is consistent between the WRF Model and both satellite estimates and is ahead of the main convective envelope over the sea seen in Figs. 8 and 9. In the WRF Model, the most organized offshore propagation to the north of Java and on both sides of Sumatra is also found in 
Average rain-rate over land
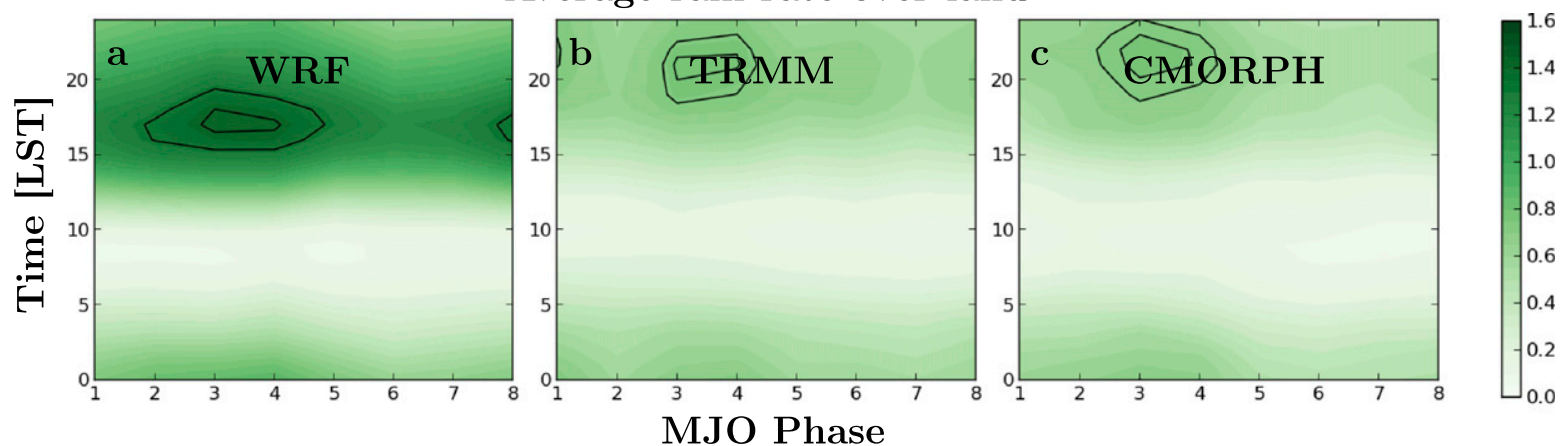

Average rain-rate over sea
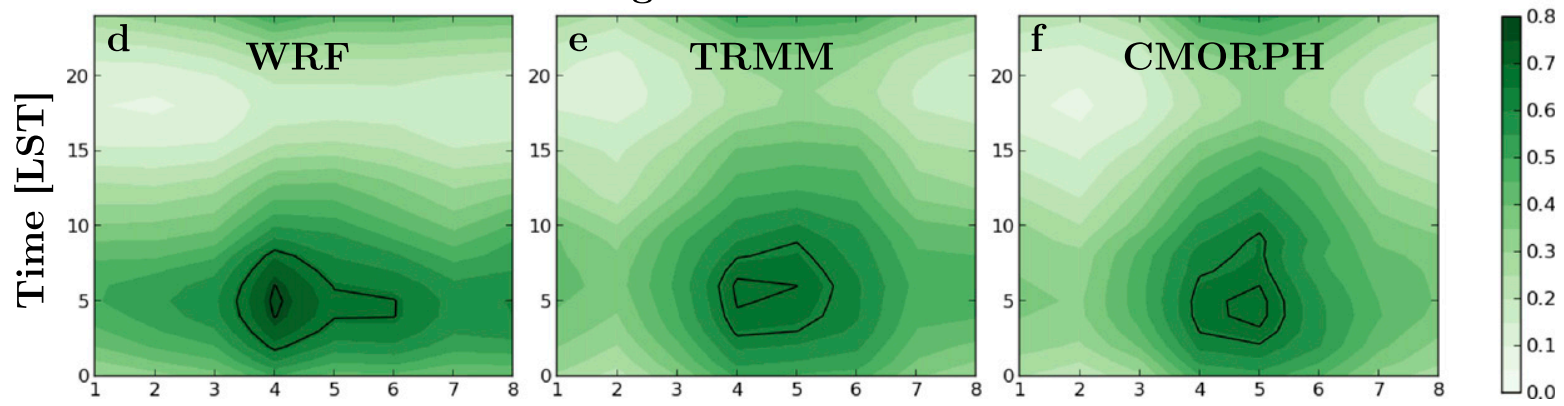

MJO Phase

FIG. 10. As in Fig. 8, but for New Guinea.

these phases. This is consistent with the satellite estimates for Sumatra. For Java, the organization of the offshore propagation is unclear, although there is an offshore precipitation maximum $200 \mathrm{~km}$ to the north of Java in phases 4-5, which is absent in the WRF Model and may be an effect from the north-south-oriented coastline of Sumatra to the west of the transect. Nonetheless, the transects over Java and Sumatra do show clear modulation of both rain rate over the land and the organization of offshorepropagating systems with $\mathrm{MJO}$ phase.
Over New Guinea (Fig. 14), the variation with MJO phase is less clear, as already seen in Fig. 10. This may be due to the steeper topography that provides stronger orographic lifting such that convection is initiated regardless of MJO phase, consistent with arguments of Bergemann and Jakob (2016), who showed that in a coastal environment, precipitation may occur in drier background conditions than would normally be expected over the sea. Further, there is pronounced variation in rainfall with $\mathrm{MJO}$ phase from around $500 \mathrm{~km}$
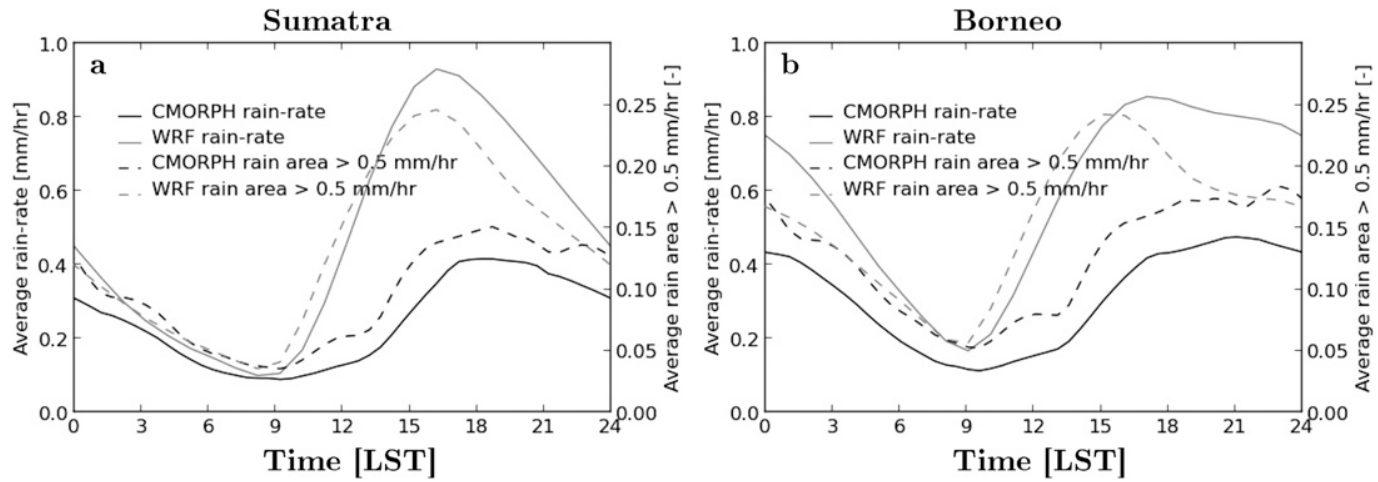

FIG. 11. Average austral summer diurnal cycle of rain-rate (solid lines) and rain-area fraction $>0.5 \mathrm{~mm} \mathrm{~h}^{-1}$ (dashed lines) over (a) Sumatra and (b) Borneo for MJO amplitude $>1$ for WRF simulations (gray) and CMORPH observations (black). 
WRF
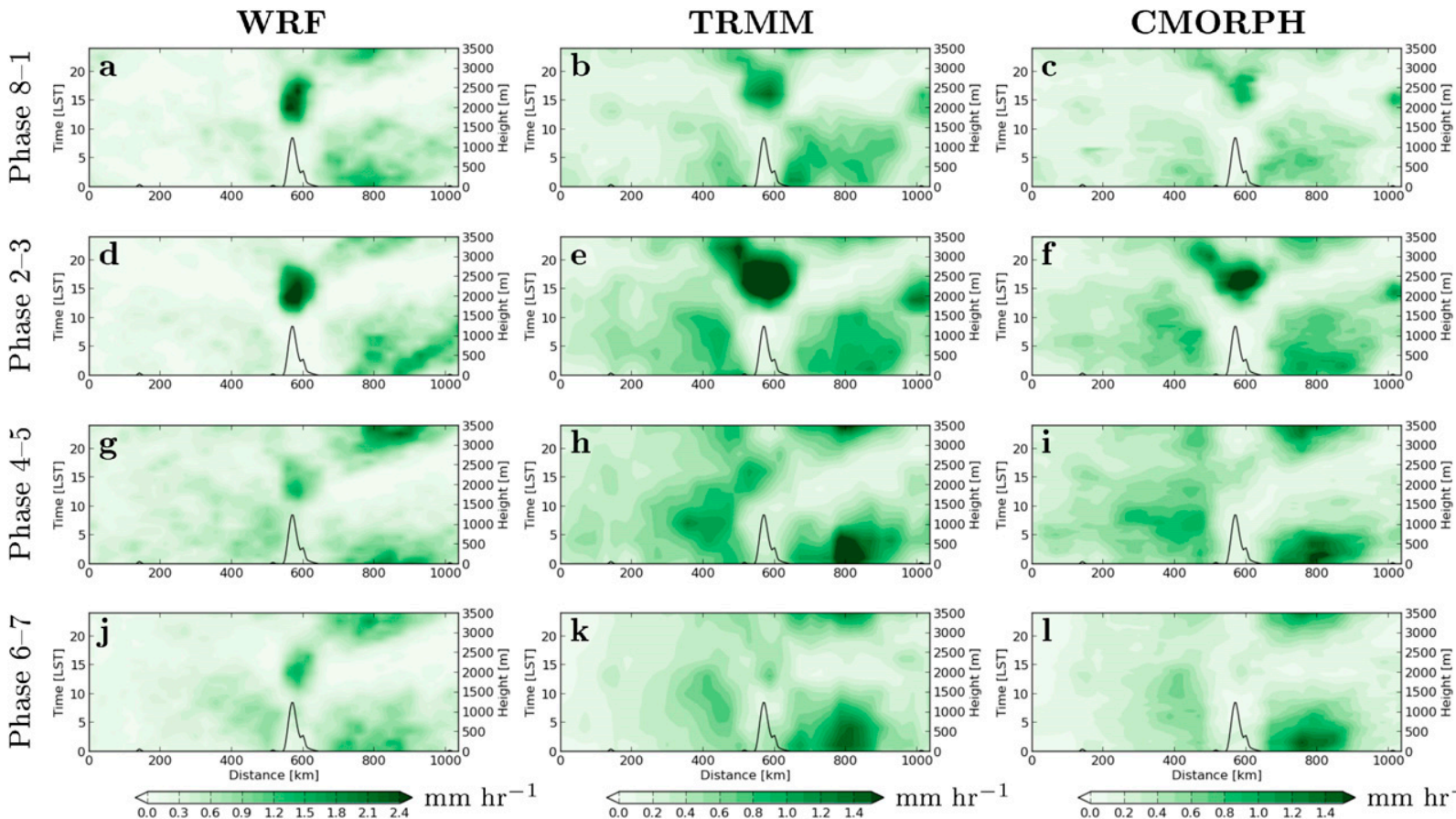

FIG. 12. Average austral summer precipitation on a transect through Java by MJO phase, for MJO amplitude $>1$, for (a),(d),(g),(j) WRF, (b),(e),(h),(k) TRMM, and (c),(f),(i),(l) CMORPH. $x=0$ corresponds to the red dot in Fig. 7. The black line shows the topography height.

northeast of New Guinea to the end of the transect that does not appear to have a diurnal component. This may be linked with the path of maximum MJO variance discussed by $\mathrm{Wu}$ and Hsu (2009), who identify a maximum of MJO-scale variance northeast of New Guinea. That this variation is not reproduced in the WRF Model (where coastally initiated offshore propagation continues until around $800 \mathrm{~km}$ offshore) is consistent with the errors in MJO variance in the WRF Model already identified northeast of New Guinea (Fig. 6).

All the transects indicate that afternoon peaks in precipitation over the highest topography occur systematically earlier in the model than in the satellite precipitation estimates, as already noted. The cross sections reveal a slight spatial offset in the location of the main afternoon/evening precipitation peak. In the WRF Model simulations, this is coincident with the ridge line of the topography, while in the satellite estimates it is over the steep slopes near the ridge. This small, spatial offset leads to the large timing errors over the slopes of steep topography seen in Fig. 5.

The tendency for afternoon precipitation to develop first over the steeper slopes is most obvious in New Guinea, where the model topography height on the specified cross section reaches $3000 \mathrm{~m}$ (the highest point in New Guinea is actually $4884 \mathrm{~m}$ toward the northwest end of the island). Interestingly, the WRF Model also develops precipitation on the slopes in a similar way to the satellite precipitation estimates, but it also shows a distinct onset right over the ridge earlier in the afternoon at around 1500 LST that is entirely missing from the satellite precipitation estimates. This gap in precipitation over the ridge in the satellite precipitation estimates is also seen in Peatman et al. (2014), Love et al. (2011), Vincent and Lane (2016a), and Hassim et al. (2016). While it is not clear what causes this deficit over the ridge, it is interesting to note that there may be snow cover for some of the period over these highest peaks, which may contaminate the satellite precipitation estimates (e.g., Chen et al. 2013).

\section{The impact of the sea breeze}

The variations in the diurnal precipitation cycle with MJO phase are partly controlled by the intensity of the sea-breeze circulation, both from kinematic forcing from convergence and destabilization due to the propagation of the cooling phase of the tropical land breeze as a diurnal gravity wave (e.g., Mapes et al. 2003; Hassim et al. 2016; Vincent and Lane 2016a). As discussed by Vincent and Lane (2016a), such effects will only lead to deep convection in the presence of sufficient moisture, which is more abundant during the MJO active and leadup phases. The previous section showed that the WRF 
WRF
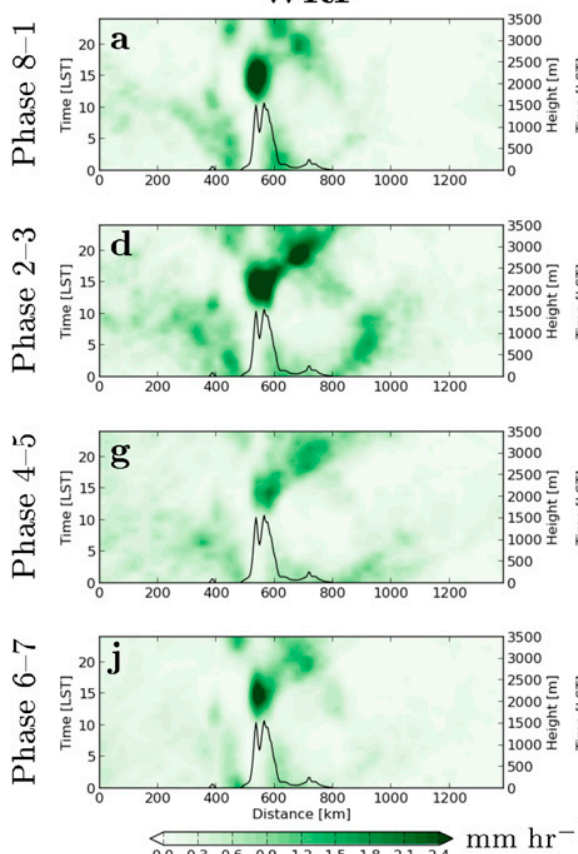

TRMM
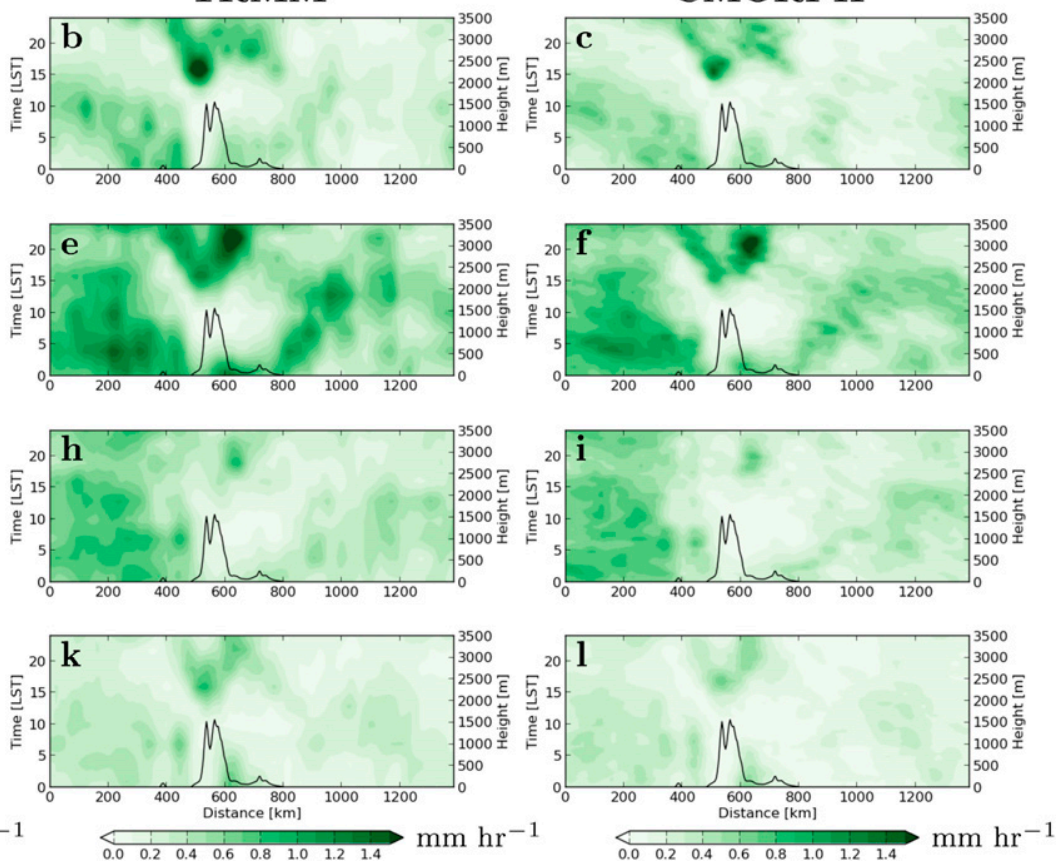

CMORPH
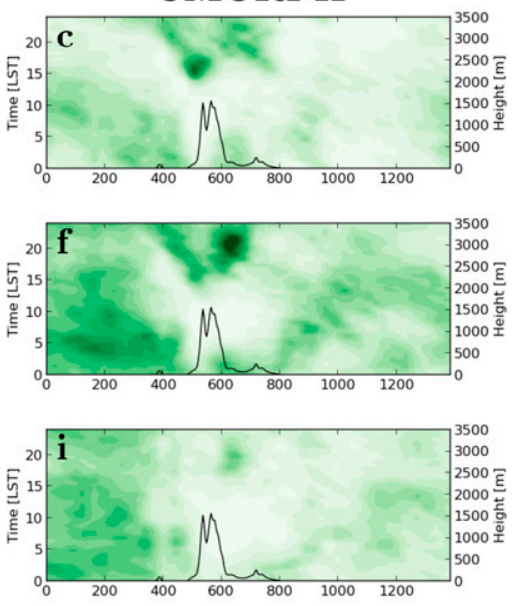

FIG. 13. As in Fig. 12, but for Sumatra.
Model simulations are producing a reasonably realistic spatial and temporal distribution of precipitation, despite a wet bias over the land and the lack of precipitation over the ocean that may indicate a failure of diurnally forced gravity waves to trigger enough convection. Since the WRF simulations produce an internally consistent dataset, these biases do not preclude them from being a useful tool to examine the dynamics
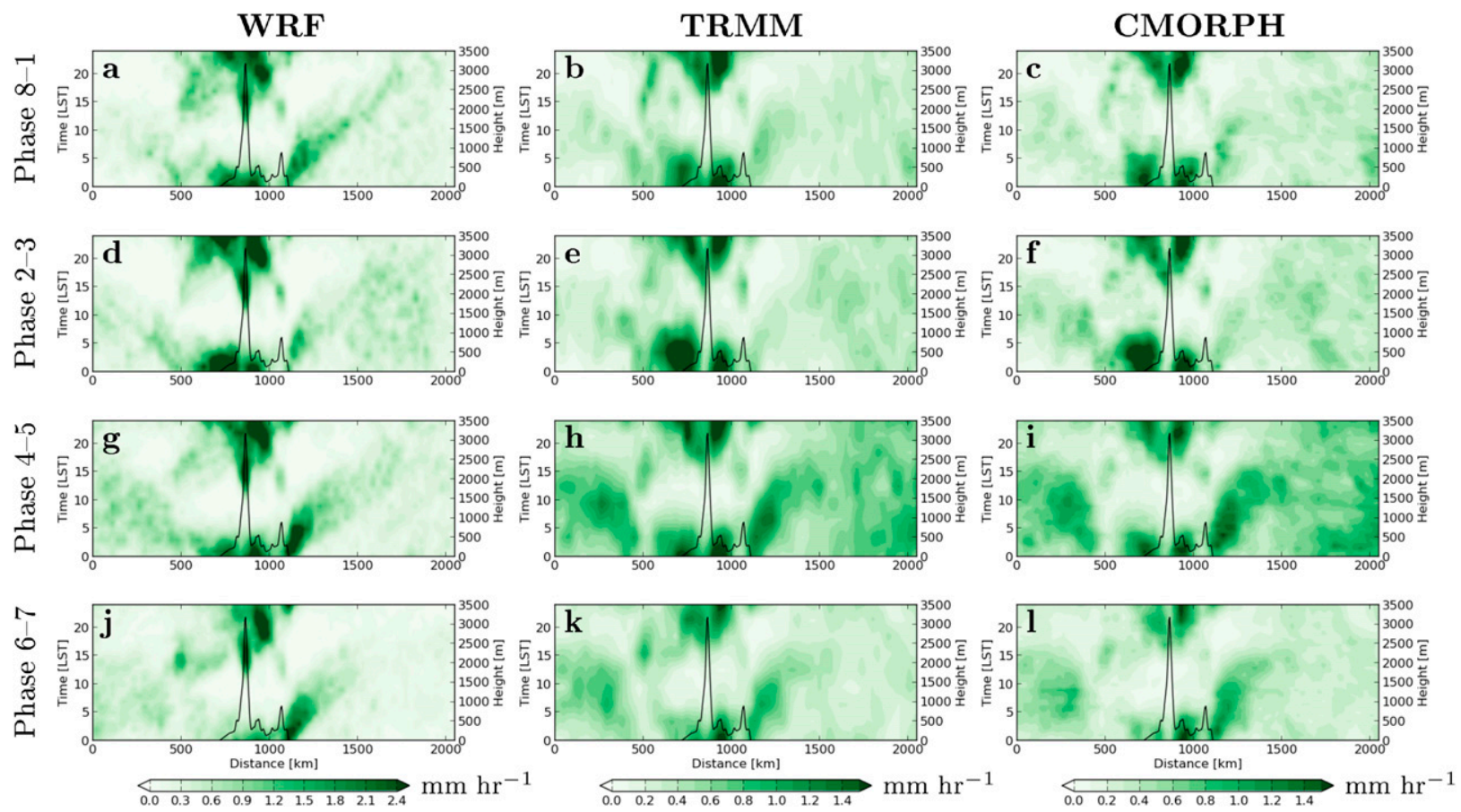

FIG. 14. As in Fig. 12, but for New Guinea. 

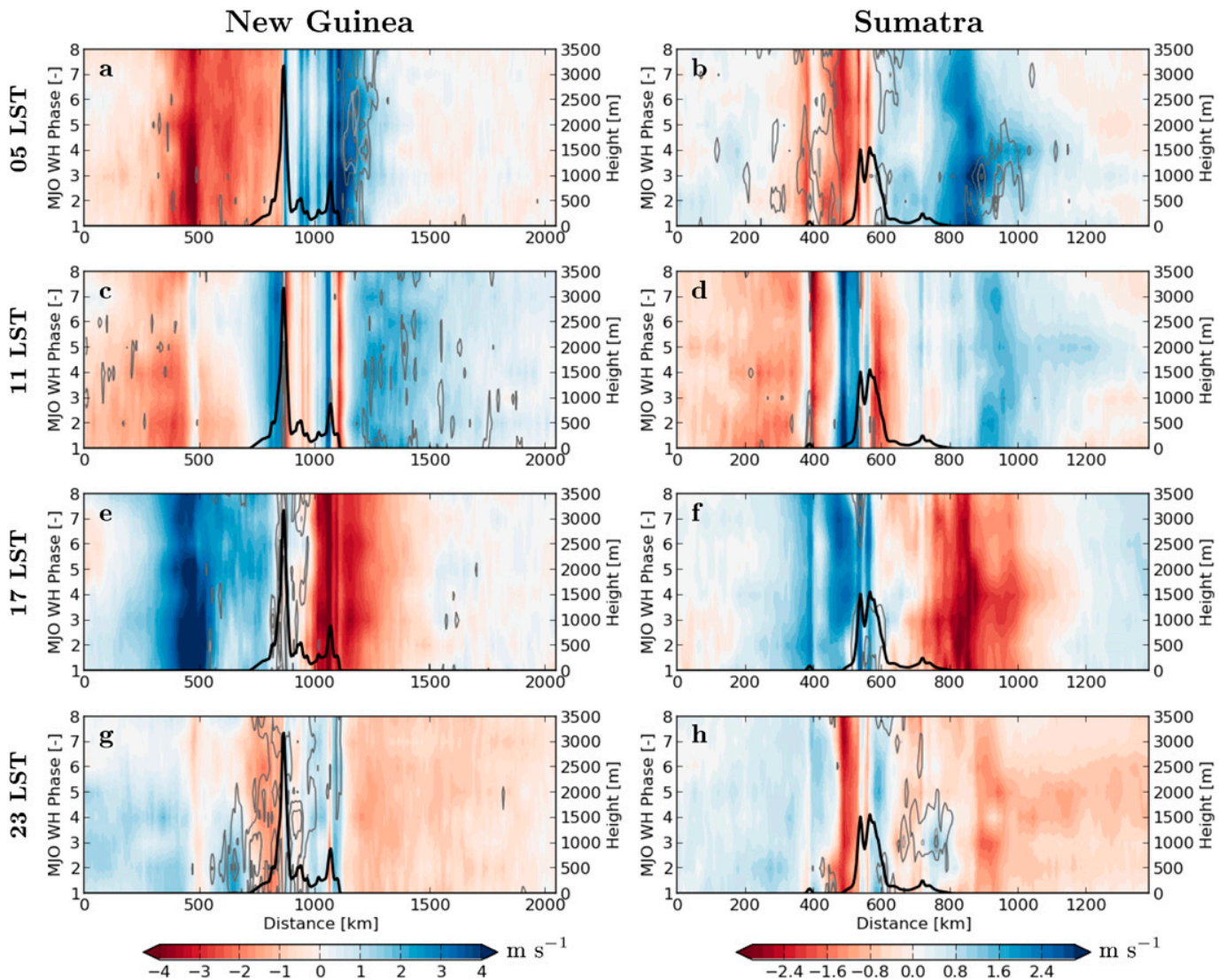

FIG. 15. Variation of simulated austral summer surface wind perturbations parallel to the transects in Fig. 7 with MJO phase at 0500, 1100, 1700, and 2300 LST for cross sections through (a),(c),(e),(g) New Guinea and (b),(d),(f),(h) Sumatra for MJO amplitude $>1$. Wind perturbations are defined as differences from the daily mean, and the wind is for the lowest model level $(26 \mathrm{~m})$. Thin line contours show precipitation of 1 (dark gray) and $3 \mathrm{~mm} \mathrm{~h}^{-1}$ (light gray). Thick black line shows topography height. Transects run in the same direction as in Figs. 12 to 14. Blue indicates flow toward the northeast and red indicates flow toward the southwest.

that cannot be readily observed by satellite. Here, we examine the variation in simulated sea-breeze circulation with MJO phase.

In Fig. 15, the simulated perturbation surface wind component in the direction of the cross sections through New Guinea and Sumatra (Fig. 7) is shown as a function of the MJO phase, where perturbations are defined by subtracting the daily mean for each day at each grid point. The results for Java are omitted, as they are similar to those for Sumatra. In both cases, blue shading indicates flow to the northeast and red indicates flow to the southwest. The respective land-breeze and seabreeze perturbations are well established for a distance of $100-200 \mathrm{~km}$ from the coast for both islands. However, over the land, local orographic flows are seen to dominate the main sea-breeze circulation and at the transitional times of 1100 and 2300 LST, these local anabatic and katabatic flows oppose the sea-breeze circulation because they respond faster to surface heating and cooling, consistent with the gradual increase in precipitation from 0900 LST and a more rapid increase from 1300 LST seen in Fig. 11.

There is a notable modulation of the sea- and landbreeze circulation with MJO phase, consistent with Birch et al. (2016), who found a maximum in the sea breeze around Sumatra in MJO phase 4. In Fig. 16, the sea-breeze anomaly averaged over a distance of $50 \mathrm{~km}$ inland and 50-100 km offshore from the northeast coasts of Sumatra New Guinea are shown. Over the coast (red lines), we see a slight reduction in the strength of the offshore (positive) flow and to some extent the onshore (negative) flow around the MJO active phases-this minimum occurs in phase 4-5 for Sumatra and phase 6 for New Guinea. Farther offshore (gray lines), there is actually an increase in the strength of the sea- and landbreeze circulation around the MJO active phases, particularly for Sumatra. Inspection of Fig. 15 suggests that this is mainly due to the increased offshore extent of both the land- and sea-breeze anomalies during the MJO active phase. This interesting pattern may reflect a 

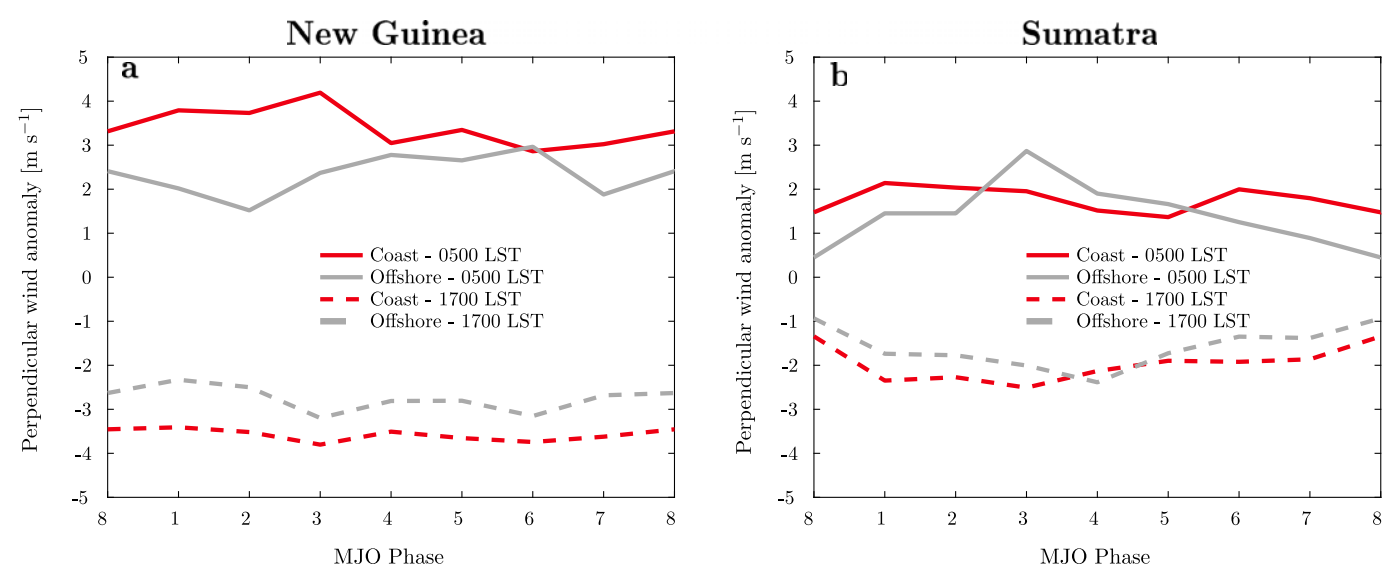

FIG. 16. Variation of the simulated austral summer surface sea-land-breeze anomaly with MJO phase, averaged over a distance of $50 \mathrm{~km}$ inland from the northeast coast and $50-100 \mathrm{~km}$ offshore for (a) New Guinea and (b) Sumatra.

weaker density current (due to the suppressed radiational cooling over the land during the convective envelope) and an increased seaward extent of the diurnal gravity wave (which depends on, among other things, the vertical scale of the diabatic heating and the background wind). On both sides of Sumatra, the heaviest rainfall occurs in $\mathrm{MJO}$ phases $2-4$, so that the variation in precipitation is skewed toward the phases immediately prior to the MJO more than the variation in sea-breeze strength. Around New Guinea, there is no obvious modulation of precipitation amount with the MJO, which may reflect the steeper topography that initiates coastally influenced precipitation even in conditions of suppressed background moisture, consistent with Bergemann and Jakob (2016).

The reason for the stronger variation in sea-breeze circulation around Sumatra than around New Guinea is not known, but we speculate that it maybe be due to the more east-west orientation of Sumatra relative to New Guinea making the sea breeze more susceptible to modification by the westerly burst of the MJO. Alternatively, the WRF Model has a large error in MJO-scale rainfall variability to the northeast of New Guinea (Fig. 6), so the modeled variation in sea-breeze circulation may also have large errors. Finally, the orographic flows associated with the steeper topography of New Guinea may mask the MJO-scale variation more than in Sumatra.

\section{Discussion}

The simulated large-scale variations in convection and precipitation that are considered classical signatures of the MJO closely resemble those in satellite precipitation estimates (Fig. 6). For example, the largest positive precipitation anomalies are seen in MJO WH04 phases 4 and 5 , while the maximum rain rate over the land occurs
1-2 MJO phases ahead of that over the sea as found by Peatman et al. (2014), Vincent and Lane (2016a), Birch et al. (2016), and others. Furthermore, there is very good consistency between the simulated and observed anomalies in the finer-scale variation across the major MC islands, such as the positive precipitation anomaly over the southwest side of Borneo and negative anomaly on the northeast side in phases $2-3$ and the negative anomaly along the mountain ridge on the southwest side of Sumatra in phases 4-5. However, some other features are not reproduced accurately. The large observed variation in precipitation anomaly on the Malay Peninsula in phases $2-5$ is not evident in the simulations, and there are areas over the sea to the southwest of Sumatra and northeast of New Guinea that show large errors in most MJO phases. These errors are likely a combination of incorrect propagation of the MJO itself and errors in the model response to the MJO, particularly over the ocean.

The WRF Model showed a strong wet bias over the land and dry bias over the water relative to satellite precipitation estimates, consistent with many previous studies in both tropical and midlatitude regions (e.g., Skok et al. 2016; Bhatt et al. 2016; Vincent and Lane 2016a), but it was consistent with the satellite estimates in many aspects of the spatial variation in rainfall (Fig. 2). The main contributor to the large errors over the land was the exaggerated diurnal precipitation cycle, as also noted by Skok et al. (2016), Bhatt et al. (2016), and others. Despite these large errors, there was good agreement in the spatial variation in the phase of the diurnal precipitation cycle between the simulations and satellite estimates, other than over the steepest topography. The large timing errors over the steep slopes related primarily to the spatial discrepancy in the position of the onset of afternoon precipitation, which occurred over the peak of the topography in the WRF 
Model and over the adjacent slopes in the satellite estimates. There was clear evidence of offshore propagation of precipitation around the major MC islands in both the WRF Model and the satellite estimates.

Inspection of the area-averaged rain rate over the sea and land with MJO phase over Java, Sumatra, and New Guinea (Figs. 8, 9, 10) reveals that over the land, the amplitude of the variation in simulated rain rate with the MJO phase is too small compared to the observations, despite the rain rates being heavier overall. Over Sumatra, the lowest afternoon rainfall occurs in phase 5 in both simulated and observed data. However, in the simulations, there is less difference in rainfall before and after phase 5 , while in the satellite estimates the maximum rainfall is located in phase 2, with only a weak secondary maximum in phases 6-7. This asymmetry between the precipitation in the MJO phases preceding and following the MJO active phase suggests that despite both periods being characterized by relatively clearer skies, the difference in moisture availability modulates the amount of precipitation. The fact that the WRF Model responds in a similar way to both these periods may indicate that it is too sensitive to orographic forcing and not sensitive enough to moisture availability. Over Java, the afternoon precipitation is nearly constant with the MJO phase in the WRF Model, while the satellite estimates show a similar pattern to that over Sumatra. Similarly, over New Guinea, the WRF Model shows only a slight decrease in afternoon rain rate in MJO phases 5-7 compared to a more pronounced decrease in the satellite estimates.

The results have implications for understanding the interactions between intraseasonal variability and the diurnal precipitation cycle in the MC. Some of these interactions were clearly simulated, suggesting that the WRF Model is suitable for physical process studies, but importantly the variation in diurnal cycle with $\mathrm{MJO}$ phase is suppressed. Analysis of the sea breeze on cross sections through New Guinea and Sumatra indicates a clear separation of the mountain/valley winds, which are established earlier in the day, and the sea-land-breeze circulation that is established in the late afternoon and evening. These distinct processes are reflected in the diurnal precipitation cycle, which is seen to initiate locally around the topographic peaks during the afternoon and evolve into organized offshore-propagating systems during the night. The model skill in reproducing the diurnal precipitation cycle over the land and sea relies on an accurate representation of the relative contribution of orographic forcing, convergence from the main sea-land-breeze disturbances, and far offshore destabilization due to the cooling phase of the land-sea-breeze circulation.
Several clear deficiencies in model performance are identified. The exaggerated diurnal precipitation cycle over the land is a model shortcoming, as is the apparent error in the timing of the diurnal precipitation peak over the land, although the true error is difficult to quantify due to the reported lag in the satellite precipitation estimates. Aside from creating errors in the diagnosis of precipitation, these errors may lead to upscale errors in diabatic heating and cooling through the deep convective layer and modulation of environmental winds. The large positive bias in precipitation over the land may be related to amplified surface heating, overactive mixing, or the updraft strength and rate of entrainment. Comparison of 2-m temperatures from the WRF Model simulations with those in the ERA-Interim (not shown) does not indicate any significant bias, suggesting that the overactive precipitation in the WRF Model is probably not simply a function of amplified surface heating. The symmetry of the sea-breeze circulation about the MJO active period and corresponding asymmetry of the precipitation is a result that should be further validated using modeling and observations.

The choice to run the model at $4 \mathrm{~km}$ was a necessary compromise based on computing considerations, given the large domain size and long simulation period. Some of these errors might be partly mitigated by running at a higher resolution, in particular the ability of the model to resolve shallow convection and the transition from shallow to deep convection. Hassim et al. (2016) found limited sensitivity to resolution when comparing the WRF Model with horizontal grid lengths of 4 and $1.33 \mathrm{~km}$ over Darwin in terms of bias in rain rate but did qualitatively note increased organization of convection at higher resolution.

\section{Conclusions}

We used the WRF Model to simulate 10 austral summer seasons over the whole MC, with a horizontal grid length of $4 \mathrm{~km}$. As well as resolving mesoscale features typical of a model of this resolution, such as the sea-breeze circulation, organized convection, and mountain/valley winds, the simulations also included planetary-scale variability because of the large domain size and because the atmosphere was nudged toward to the ERA-Interim above the boundary layer for wavelengths longer than $1000 \mathrm{~km}$. Comparison of precipitation fields from the WRF Model with the satellite precipitation products TRMM and CMORPH revealed consistent patterns in the variation of rain rate with the MJO, time of day, and proximity to coastlines and topography, despite a positive precipitation bias over the land in the WRF Model. 
TABLE A1. Description of the control model simulation configuration.

\begin{tabular}{|c|c|c|}
\hline Parameter & Both domains & \\
\hline Planetary boundary layer scheme & MYJ TKE (Mellor and Yamada 1982) & \\
\hline Surface layer scheme & Eta similarity (Janjić 1996) & \\
\hline Microphysics parameterization & WRF single-moment 6-class (WSM6; Hong and Jeong-Ock 2006) & \\
\hline Longwave radiation scheme & RRTM (Mlawer et al. 1997) & \\
\hline Shortwave radiation scheme & Goddard (Chou and Suarez 1994) & \\
\hline Land surface scheme & Noah (Mitchell et al. 2005) & \\
\hline \multirow[t]{2}{*}{ Vertical levels } & 79 & \\
\hline & 12-km domain & 4-km domain \\
\hline Cumulus parameterization scheme & Kain-Fritsch (Kain and Fritsch 1992) & N/A \\
\hline Spectral nudging cutoff & $1000 \mathrm{~km}$ & N/A \\
\hline Nudging coefficient & $0.0003 \mathrm{~s}^{-1}$ (all nudged variables) & N/A \\
\hline Grid points (west-east $\times$ north-south) & $732 \times 295$ & $1641 \times 534$ \\
\hline
\end{tabular}

Analysis of the bivariate relationship of rain rate with time of day and MJO phase showed that the rain rate varies on both time scales, with the largest diurnal cycle occurring 1-2 MJO WH04 phases ahead of the main MJO envelope over the water. These patterns were consistent between the modeled and observed rain rates, although the variation in diurnal cycle with MJO phase was suppressed in the WRF Model compared with the satellite observations. The diurnal cycle in area-averaged rain rates over the land and sea showed that in the satellite precipitation estimates heavy rain developed more slowly, peaked later, and continued further into the night than in the WRF Model, indicating a possible problem with the transition to stratiform rain in the model.

Transects through the main mountain ridges of Java, Sumatra, and New Guinea showed persistent offshore propagation from both sides of each island in the WRF Model and satellite precipitation estimates. Comparison with the land-sea-breeze anomalies revealed that offshore-propagating precipitation tends to follow the offshore extent of the seaward branch of the land-sea-breeze anomaly, which propagates far offshore in agreement with tropical sea-breeze theory (e.g., Rotunno 1983). Despite the similarity in seabreeze anomaly across all phases of the MJO, the most extensive offshore propagation of precipitation is found in the lead-up and active MJO phases, reflecting the higher moisture availability. While the land-sea breeze was relatively uninterrupted over Java, the more complex topography of Sumatra and New Guinea caused competing influences from local katabatic and anabatic flows, which disturbed the establishment of the main land- and sea-breeze anomalies. There was only a slight modulation of the offshore extent of the land-seabreeze anomaly with MJO phase, suggesting that the strength of the sea-breeze circulation is of secondary importance compared to the variation in moisture availability. Validating the simulated offshore extent of the sea-breeze circulation and its variation with MJO phase is an important extension to the work presented here and could possibly be achieved using satellitederived surface wind speeds over the sea.

This work has simulated longer time periods over a larger domain than other recent studies and has demonstrated that the WRF Model with a horizontal resolution of $4 \mathrm{~km}$ is an excellent tool for process studies relating to convection in the tropics, despite some biases in the amplitude of the diurnal precipitation cycle over the land. The study has demonstrated the multiscalar interplay between larger-scale modes of variability like the MJO and mesoscale processes in the complex topography of the MC. Future work will focus further on the evolution of the profiles of heat, moisture, and wind with the evolution of MJO and time of day and on the modulation of such patterns with other modes of variability such as ENSO and the East Asian and Australian monsoons.

Acknowledgments. This work was funded by the Australian Research Council's Centre of Excellence program (CE110001028). The WRF Model simulations for this research were undertaken on the NCI National Computing Facility in Canberra, Australia, which is supported by the Australian Commonwealth Government. Thank you to Paola Petrelli (NCI) for assistance in publishing the dataset. Thank you to two anonymous reviewers for insightful comments.

\section{APPENDIX}

\section{Sensitivity Studies}

Prior to running the 10-yr austral summer simulations used in this study, a set of sensitivity experiments 
TABLE A2. Model physics experiments.

\begin{tabular}{cl}
\hline \hline Expt & \multicolumn{1}{c}{ Difference from control } \\
\hline 1 & YSU planetary boundary layer scheme (Hong et al. 2006), MM5 MO scheme \\
2 & MYNN planetary boundary layer scheme (Nakanishi and Niino 2009), MM5 MO scheme \\
3 & Betts-Miller cumulus scheme on 12-km domain (Janjic 1994) \\
4 & WRF double-moment 6-class (WDM6) microphysics scheme (Lim and Hong 2010) \\
5 & Thompson microphysics scheme (Thompson et al. 2004) \\
6 & WRF, version 3.5, YSU PBL scheme \\
7 & WRF, version 3.5, YSU PBL scheme, GRIMS shallow cumulus scheme (Hong et al. 2013)
\end{tabular}

was conducted to guide the choice of model physics and to assess the impact of running continuous 90-day simulations with nudging but without reinitializing the model. In this appendix, we describe the design and results of the sensitivity study (section a) and demonstrate that the simulated large-scale variability in precipitation remains in phase with that in the TRMM precipitation estimates (section $b$ ).

\section{a. Choice of model physics}

Model physics were varied relative to a control setup as described in Table A1. Sensitivity experiments were identical to the control, except with the changes listed in Table A2. Various diagnostics were applied to the tests, but the primary diagnostic was the area-averaged diurnal precipitation cycles over the land and sea, reflecting the focus of this study. In each experiment, only one setting was varied from the control, except for the PBL schemes where the recommended associated changes to the surface layer scheme were made.
The seven sensitivity experiments are described in Table A2 relative to their difference from the control setup. The control and experiments 1-5 were run with WRF, version 3.3. Since the Global/Regional Integrated Model system (GRIMs) shallow cumulus scheme was not available in this version and operates together with the Yonsei University (YSU) PBL scheme, experiments 6 and 7 were run with WRF, version 3.5, and the YSU planetary boundary layer scheme. Sensitivity experiments were run for a 2-week test period.

Area-averaged diurnal precipitation cycles for the 2-week sensitivity experiments, together with TRMM and CMORPH estimates, are shown in Fig. A1. The errors in the diurnal precipitation cycle over the land are largely insensitive to the model physics. The timing of the afternoon precipitation peak is improved by several hours with the Mellor-Yamada-Nakanishi-Niino (MYNN) PBL scheme relative to the YSU and MYJ schemes, but this scheme shows larger errors over the water. To minimize errors over both the land and the sea, the MYJ scheme was chosen. The choice of cumulus

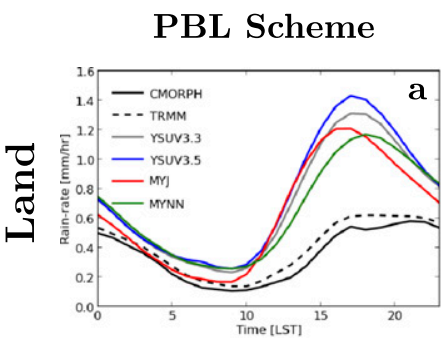

$\mathrm{Cu}$ Scheme (d01)
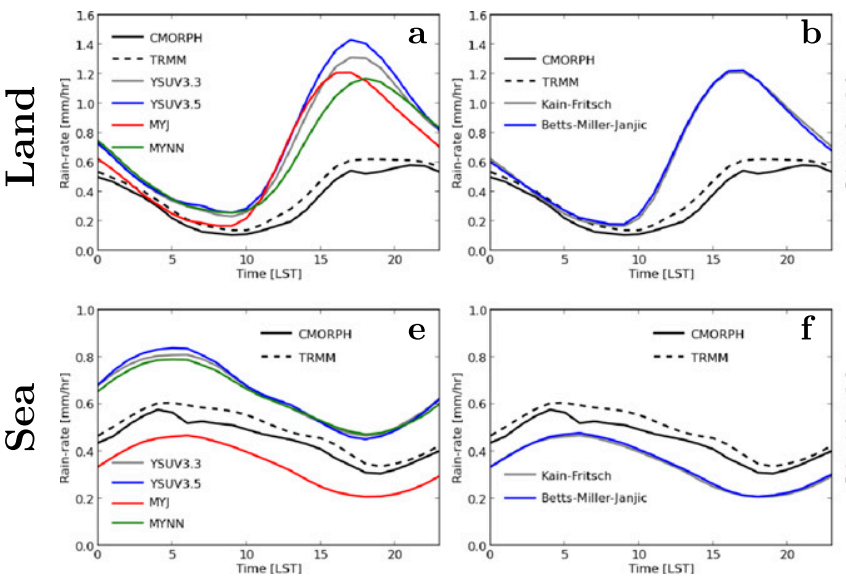

MP Scheme
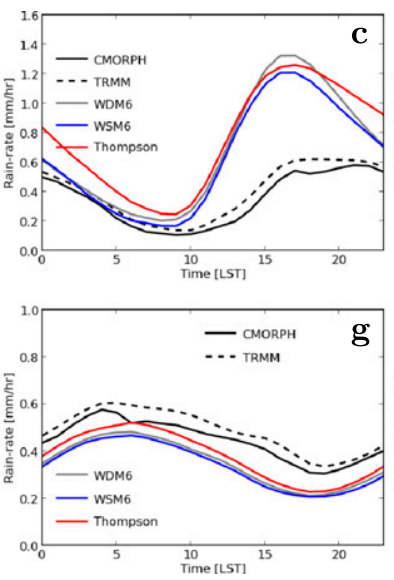

Shallow Cu Scheme
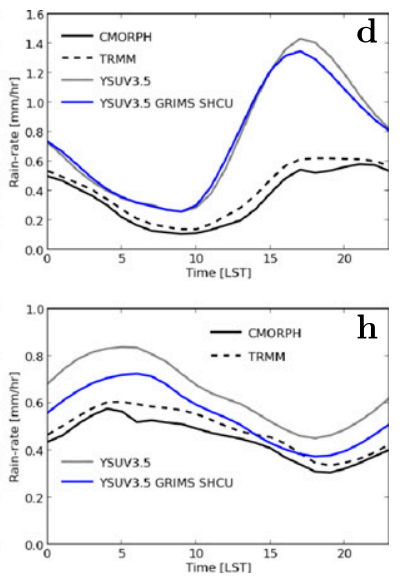

FIG. A1. Area-averaged diurnal precipitation cycle (4-km domain) over the (a)-(d) land and (e)-(h) sea for comparisons of PBL schemes, cumulus (CU) parameterization on the 12-km domain, microphysics (MP) schemes, and inclusion of shallow cumulus scheme. TRMM and CMORPH estimates are shown in solid and dashed black lines, respectively. WRF and CMORPH data are averaged to the TRMM $0.25^{\circ} \times 0.25^{\circ}$. 

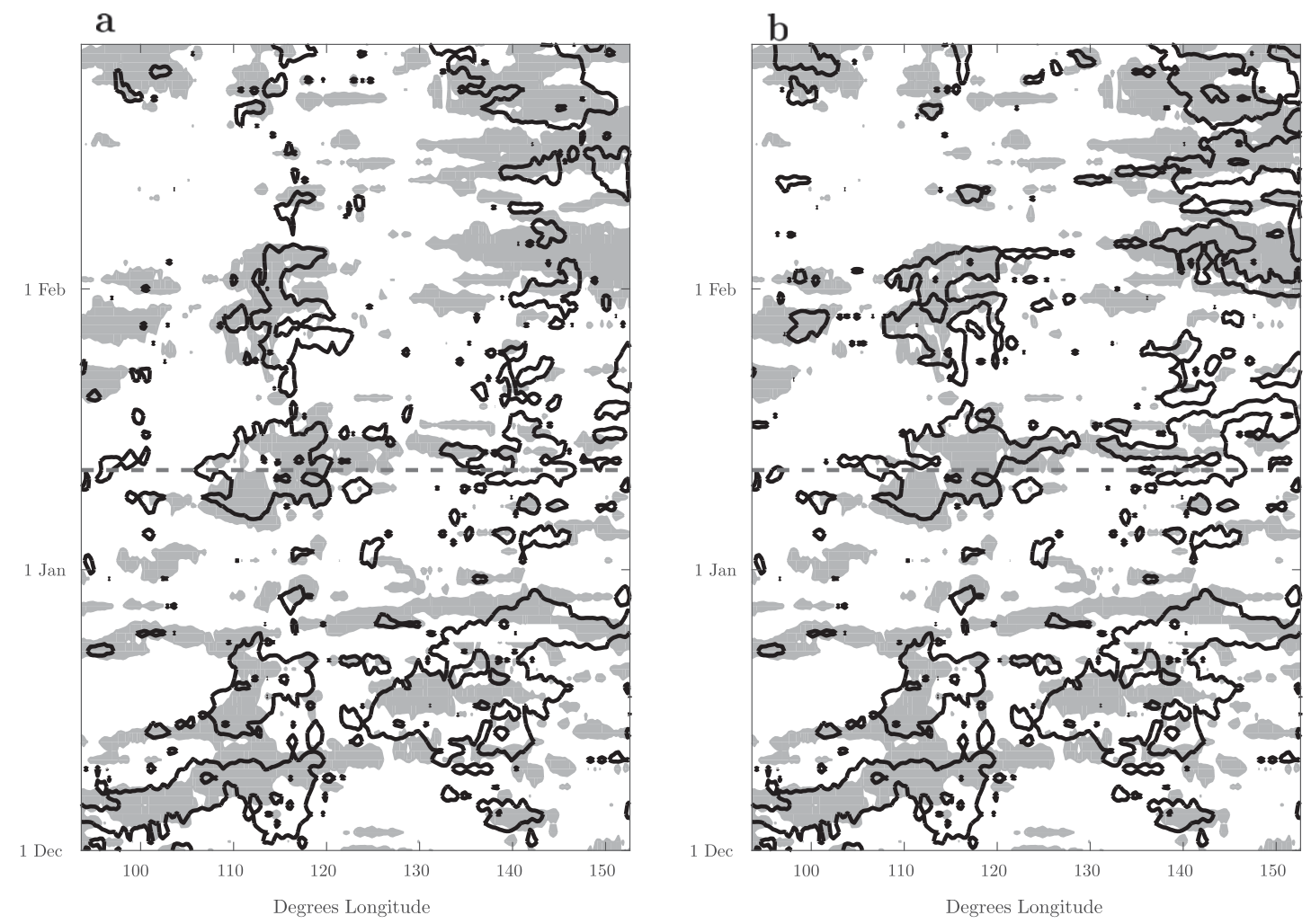

FIG. A2. Hovmöller diagrams showing $15 \mathrm{~mm} \mathrm{~h}^{-1}$ contour for meridionally averaged precipitation for TRMM (gray shading) and the WRF 4-km domain (black lines). (a) Simulation run continuously for 90 days. (b) Simulation reinitialized on 13 Jan (indicated by dashed horizontal line).

scheme on the $12-\mathrm{km}$ domain makes almost no difference to the diurnal precipitation cycle on the 4-km domain, but inspection of longer runs suggested that incorrect tropical cyclone-like structures occasionally occurred in the 12-km domain with the Kain-Fritsch scheme, so the Betts-Miller scheme was chosen. Similarly, the different microphysics schemes and shallow cumulus scheme made little difference, and the control settings for these schemes were retained.

\section{b. Impact of running without reinitialization}

To ascertain whether running the model continuously for 90 days would result in degradation of largescale weather patterns, one season was reinitialized after 44 days. In Fig. A2, Hovmöller diagrams of rain rates $>15 \mathrm{~mm} \mathrm{~h}^{-1}$ are shown for WRF and TRMM for a continuous 90-day run (control) and a version restarted on 13 January using ERA-Interim initial conditions. The two plots are identical up to $13 \mathrm{Janu}$ ary, after which they diverge slightly because of the reinitialization. The main differences are on the eastern side of the domain, where the eastwardpropagating events in the beginning and middle of February appear more organized in the reinitialized experiment. These comparisons lead us to conclude that there might be some benefits in some cases to reinitialized simulations; however, the advantages of having continuous runs over the 3 -month periods outweighed these benefits.

\section{REFERENCES}

Bergemann, M., and C. Jakob, 2016: How important is tropospheric humidity for coastal rainfall in the tropics? Geophys. Res. Lett., 43, 5860-5868, doi:10.1002/2016GL069255.

Bhatt, B. C., S. Sobolowski, and A. Higuchi, 2016: Simulation of diurnal rainfall variability over the maritime continent with a high-resolution regional climate model. J. Meteor. Soc. Japan, 94A, 89-103, doi:10.2151/jmsj.2015-052.

Birch, C., S. Webster, S. C. Peatman, D. Parker, A. Matthews, Y. Li, and M. Hassim, 2016: Scale interactions between the MJO and the western Maritime Continent. J. Climate, 29, 2471-2492, doi:10.1175/JCLI-D-15-0557.1.

Chang, C.-P., P. A. Harr, and H.-J. Chen, 2005: Synoptic disturbances over the equatorial South China Sea and western Maritime Continent during boreal winter. Mon. Wea. Rev., 133, 489-503, doi:10.1175/MWR-2868.1.

Chen, S., and Coauthors, 2013: Evaluation of the successive V6 and V7 TRMM multisatellite precipitation analysis over the continental United States. Water Resour. Res., 49, 8174-8186, doi:10.1002/2012WR012795. 
Chou, M.-D., and M. J. Suarez, 1994: An efficient thermal infrared radiation parameterization for use in general circulation models. NASA Tech. Memo. 104606, 93 pp.

Climate Prediction Center, 2011: NOAA CPC morphing technique (CMORPH) global precipitation analyses 30 minute estimates at $8 \mathrm{~km}$ resolution. Accessed 1 August 2015. [Available online at http:/ftp.cpc.ncep.noaa.gov/precip/CMORPH_V1.0/RAW/ $8 \mathrm{~km}-30 \mathrm{~min} /$.

Dee, D. P., and Coauthors, 2011: The ERA-Interim reanalysis: Configuration and performance of the data assimilation system. Quart. J. Roy. Meteor. Soc., 137, 553-597, doi:10.1002/ qj.828.

Dirmeyer, P. A., and Coauthors, 2012: Simulating the diurnal cycle of rainfall in global climate models: Resolution versus parameterization. Climate Dyn., 39, 399-418, doi:10.1007/ s00382-011-1127-9.

Feng, J., T. Li, and W. Zhu, 2015: Propagating and nonpropagating MJO events over Maritime Continent. J. Climate, 28, 84308449, doi:10.1175/JCLI-D-15-0085.1.

Gemmill, W. B., B. Katz, and X. Li, 2007: Daily real-time, global sea surface temperature: High-resolution analysis: RTG_SST_HR. NCEP/EMC Office Note Marine Modeling and Analysis Branch Contribution Number 260, 39 pp.

Gianotti, R. L., D. Zhang, and E. B. Eltahir, 2012: Assessment of the regional climate model version 3 over the Maritime Continent using different cumulus parameterization and land surface schemes. J. Climate, 25, 638-656, doi:10.1175/ JCLI-D-11-00025.1.

Gille, S. T., S. G. Llewellyn Smith, and N. M. Statom, 2005: Global observations of the land breeze. Geophys. Res. Lett., 32, L05605, doi:10.1029/2004GL022139.

Goddard Space Flight Center, 1998: TRMM (Tropical Rainfall Measurement Mission) project merged HQ-infrared precipitation estimate (3B42), version 7. Accessed 1 August 2015. [Available online at $\mathrm{ftp} / / / \mathrm{disc} 2 . n a s c o m . n a s a . g o v / \mathrm{data} / \mathrm{s} 4 \mathrm{pa} /$ TRMM_L3/TRMM_3B42/.]

Hassim, M. E. E., T. P. Lane, and W. Grabowski, 2016: The diurnal cycle of rainfall over New Guinea in convection-permitting WRF simulations. Atmos. Chem. Phys., 16, 161-175, doi:10.5194/acp-16-161-2016.

Holloway, C. E., S. J. Woolnough, and G. M. S. Lister, 2012: Precipitation distributions for explicit versus parametrized convection in a large-domain high-resolution tropical case study. Quart.J. Roy. Meteor. Soc., 138, 1692-1708, doi:10.1002/ qj.1903.

,$- \ldots$, and $\_, 2013$ : The effects of explicit versus parameterized convection on the $\mathrm{MJO}$ in a large-domain highresolution tropical case study. Part I: Characterization of large-scale organization and propagation. J. Atmos. Sci., 70, 1342-1369, doi:10.1175/JAS-D-12-0227.1.

Hong, S.-Y., and J. L. Jeong-Ock, 2006: The WRF single-moment 6-class microphysics scheme (WSM6). J. Korean Meteor. Soc., 42, 129-151.

—, Y. Noh, and J. Dudhia, 2006: A new vertical diffusion package with an explicit treatment of entrainment processes Mon. Wea. Rev., 134, 2318-2341, doi:10.1175/MWR3199.1.

— , and Coauthors, 2013: The Global/Regional Integrated Model system (GRIMs). Asia-Pac. J. Atmos. Sci., 49, 219-243, doi:10.1007/s13143-013-0023-0.

Huffman, G. J., and Coauthors, 2007: The TRMM Multisatellite Precipitation Analysis (TMPA): Quasi-global, multiyear, combined-sensor precipitation estimates at fine scales. J. Hydrometeor., 8, 38-55, doi:10.1175/JHM560.1.
Ichikawa, H., and T. Yasunari, 2008: Intraseasonal variability in diurnal rainfall over New Guinea and the surrounding oceans during austral summer. J. Climate, 21, 2852-2868, doi:10.1175/ 2007JCLI1784.1.

Janjić, Z. I., 1994: The step-mountain eta coordinate model: Further developments of the convection, viscous sublayer, and turbulence closure schemes. Mon. Wea. Rev., 122, 927-945, doi:10.1175/1520-0493(1994)122<0927:TSMECM > 2.0.CO;2. 1996: The surface layer in the NCEP Eta Model. Proc. 11th Conf. on Numerical Weather Prediction, Norfolk, VA, Amer. Meteor. Soc., 354-355.

Joyce, R. J., J. E. Janowiak, P. A. Arkin, and P. Xie, 2004: CMORPH: A method that produces global precipitation estimates from passive microwave and infrared data at high spatial and temporal resolution. J. Hydrometeor., 5, 487-503, doi:10.1175/1525-7541(2004)005<0487:CAMTPG>2.0.CO;2.

Kain, J. S., and J. M. Fritsch, 1992: The role of the convective "trigger function" in numerical forecasts of mesoscale convective systems. Meteor. Atmos. Phys., 49, 93-106, doi:10.1007/ BF01025402.

Kikuchi, K., and B. Wang, 2008: Diurnal precipitation regimes in the global tropics. J. Climate, 21, 2680-2696, doi:10.1175/ 2007JCLI2051.1.

Kim, D., M. I. Lee, D. Kim, S. D. Schubert, D. E. Waliser, and B. Tian, 2014: Representation of tropical subseasonal variability of precipitation in global reanalyses. Climate Dyn., 43, 517-534, doi:10.1007/s00382-013-1890-x.

Koo, M.-S., and S.-Y. Hong, 2010: Diurnal variations of simulated precipitation over East Asia in two regional climate models. J. Geophys. Res., 115, D05105, doi:10.1029/2009JD012574.

Lim, K.-S. S., and S.-Y. Hong, 2010: Development of an effective double-moment cloud microphysics scheme with prognostic cloud condensation nuclei $(\mathrm{CCN})$ for weather and climate models. Mon. Wea. Rev., 138, 1587-1612, doi:10.1175/2009MWR2968.1.

Liu, P., A. P. Tsimpidi, Y. Hu, B. Stone, A. G. Russell, and A. Nenes, 2012: Differences between downscaling with spectral and grid nudging using WRF. Atmos. Chem. Phys., 12, 3601-3610, doi:10.5194/acp-12-3601-2012.

Love, B. S., A. J. Matthews, and G. M. S. Lister, 2011: The diurnal cycle of precipitation over the Maritime Continent in a highresolution atmospheric model. Quart. J. Roy. Meteor. Soc., 137, 934-947, doi:10.1002/qj.809.

Majda, A. J., and Q. Yang, 2016: A multiscale model for the intraseasonal impact of the diurnal cycle over the Maritime Continent on the Madden-Julian oscillation. J. Atmos. Sci., 73, 579-604, doi:10.1175/JAS-D-15-0158.1.

Mapes, B. E., T. T. Warner, and M. Xu, 2003: Diurnal patterns of rainfall in northwestern South America. Part III: Diurnal gravity waves and nocturnal convection offshore. Mon. Wea. Rev., 131, 830-844, doi:10.1175/1520-0493(2003)131<0830:DPORIN >2.0.CO;2.

Mellor, G. L., and T. Yamada, 1982: Development of a turbulence closure model for geophysical fluid problems. Rev. Geophys. Space Phys., 20, 851-875, doi:10.1029/RG020i004p00851.

Mitchell, K., and Coauthors, 2005: The Community Noah LandSurface Model (LSM) user's guide version 2.7.1. NCEP/EMC Tech. Rep., 26 pp.

Mlawer, E. J., S. J. Taubman, P. D. Brown, M. J. Iacono, and S. A. Clough, 1997: Radiative transfer for inhomogeneous atmospheres: RRTM, a validated correlated-k model for the longwave. J. Geophys. Res., 102, 16 663-16 682, doi:10.1029/97JD00237.

Nakanishi, M., and H. Niino, 2009: Meteorological society of Japan NII-electronic library service. J. Meteor. Soc. Japan, 87, 895912, doi:10.2151/jmsj.87.895. 
Neale, R., and J. Slingo, 2003: The Maritime Continent and its role in the global climate: A GCM study. J. Climate, 16, 834-848, doi:10.1175/1520-0442(2003)016<0834:TMCAIR>2.0.CO;2.

Nguyen, H., A. Protat, V. Kumar, S. Rauniyar, M. Whimpey, and L. Rikus, 2015: A regional forecast model evaluation of statistical rainfall properties using the CPOL radar observations in different precipitation regimes over Darwin, Australia. Quart. J. Roy. Meteor. Soc., 141, 2337-2349, doi:10.1002/qj.2525.

Oh, J.-H., B.-M. Kim, K.-Y. Kim, H.-J. Song, and G.-H. Lim, 2013: The impact of the diurnal cycle on the MJO over the Maritime Continent: A modeling study assimilating TRMM rain rate into global analysis. Climate Dyn., 40, 893-911, doi:10.1007/ s00382-012-1419-8.

Peatman, S. C., A. J. Matthews, and D. P. Stevens, 2014: Propagation of the Madden-Julian oscillation through the Maritime Continent and scale interaction with the diurnal cycle of precipitation. Quart. J. Roy. Meteor. Soc., 140, 814-825, doi:10.1002/qj.2161.

,$- \ldots$, and $—$, 2015: Propagation of the Madden-Julian oscillation and scale interaction with the diurnal cycle in a high-resolution GCM. Climate Dyn., 45, 2901-2918, doi:10.1007/s00382-015-2513-5.

Pfeifroth, U., J. Trentmann, A. H. Fink, and B. Ahrens, 2016: Evaluating satellite-based diurnal cycles of precipitation in the African tropics. J. Appl. Meteor. Climatol., 55, 23-39, doi:10.1175/JAMC-D-15-0065.1.

Qian, J.-H., 2008: Why precipitation is mostly concentrated over islands in the Maritime Continent. J. Atmos. Sci., 65, 14281441, doi:10.1175/2007JAS2422.1.

Rauniyar, S. P., and K. J. E. Walsh, 2013: Scale interaction of the diurnal cycle of rainfall over the MC and Australia: Influence of the MJO. J. Climate, 26, 1304-1321, doi:10.1175/ JCLI-D-12-00124.1.

Rotunno, R., 1983: On the linear theory of the land and sea breeze. J. Atmos. Sci., 40, 1999-2009, doi:10.1175/ 1520-0469(1983)040<1999:OTLTOT>2.0.CO;2.

Skok, G., N. Žagar, L. Honzak, R. Žabkar, J. Rakovec, and A. Ceglar, 2016: Precipitation intercomparison of a set of satellite- and raingauge-derived datasets, ERA Interim reanalysis, and a single WRF regional climate simulation over
Europe and the North Atlantic. Theor. Appl. Climatol., 123, 217-232, doi:10.1007/s00704-014-1350-5.

Subramanian, A. C., and G. J. Zhang, 2014: Diagnosing MJO hindcast biases in NCAR CAM3 using nudging during the DYNAMO field campaign. J. Geophys. Res. Atmos., 119, 7231-7253, doi:10.1002/2013JD021370.

Thompson, G., R. M. Rasmussen, and K. Manning, 2004: Explicit forecasts of winter precipitation using an improved bulk microphysics scheme. Part I: Description and sensitivity analysis. Mon. Wea. Rev., 132, 519-542, doi:10.1175/ 1520-0493(2004)132<0519:EFOWPU>2.0.CO;2.

Vincent, C. L., and A. N. Hahmann, 2015: The impact of grid and spectral nudging on the variance of the near-surface wind speed. J. Appl. Meteor. Climatol., 54, 1021-1038, doi:10.1175/ JAMC-D-14-0047.1.

- and T. P. Lane, 2016a: Evolution of the diurnal precipitation cycle with the passage of a Madden-Julian oscillation event through the Maritime Continent. Mon. Wea. Rev., 144, 19832005, doi:10.1175/MWR-D-15-0326.1.

$\longrightarrow$, and $-2016 \mathrm{~b}$ : Maritime Continent austral summer climatology v1.0. NCI National Research Data Collection, accessed 16 March 2017, doi:10.4225/41/5850b633c54ed.

Wheeler, M. C., and H. H. Hendon, 2004: An all-season real-time multivariate MJO index: Development of an index for monitoring and prediction. Mon. Wea. Rev., 132, 1917-1932, doi:10.1175/1520-0493(2004)132<1917:AARMMI>2.0.CO;2.

Wu, C. H., and H. H. Hsu, 2009: Topographic influence on the MJO in the Maritime Continent. J. Climate, 22, 5433-5448, doi:10.1175/2009JCLI2825.1.

Yang, G. Y., and J. Slingo, 2001: The diurnal cycle in the tropics. Mon Wea. Rev., 129, 784-801, doi:10.1175/1520-0493(2001)129<0784: TDCITT $>2.0 . \mathrm{CO} ; 2$

Zhang, C., 2013: Madden-Julian oscillation: Bridging weather and climate. Bull. Amer. Meteor. Soc., 94, 1849-1870, doi:10.1175/ BAMS-D-12-00026.1.

Zhou, L., and Y. Wang, 2006: Tropical rainfall measuring mission observation and regional model study of precipitation diurnal cycle in the New Guinean region. J. Geophys. Res., 111, D17104, doi:10.1029/2006JD007243. 